\title{
Islamic Critique and Alternative to Financial Engineering Issues
}

\author{
Masudul Alam Choudhury \\ College of Commerce \& Economics, \\ Sultan Qaboos University \& Trisakti University, \\ Postgraduate Program in Islamic Economics and Finance \\ masudc@squ.edu.om
}

\begin{abstract}
The arguments of this paper arise from the economic and methodological premises on behavior, markets and institutional structure that together influence asset-valuation. All these are bonded together to explain how methodology defines the domain of financial engineering in mainstream and Islamic perspectives. Mainstream financial engineering as a study of methods that stand upon the assumptions of behavior, markets and institutions of the neoclassical vintage is critically examined. This is contrasted with the Islamic perspectives of the same issues that outlay an altogether different methodological worldview. Different forms of asset-valuation models emerge in these two cases. The Islamic premise of behavior, markets and institutions is utilized against the backdrop of its most fundamental epistemology. This is the episteme of unity of knowledge (Tawhid). The contrary epistemological foundation of mainstream financial engineering is rationalism and rational economic, scientific, social and institutional choices. Thus the parting conceptions of financial engineering applied to asset-valuation make the mainstream and Islamic approaches distinct and opposite to each other. This paper develops and investigates an overlapping generation asset-valuation model in the Islamic epistemological context while it examines the unacceptable nature of financial engineering ideas in the mainstream case. Financial engineering in both perspectives are analytically examined against there distinct epistemological worldviews.

Referees' comments have been answered in the footnotes of this paper given towards the end. This method of answering referees' comments leaves the text of the paper intact while allaying the referees' concerns by detailed explanations.
\end{abstract}




\section{Objective}

The objective of this research project is to prove from the Shariah and logical viewpoints that many of the arguments of Islamic economics and financial experts toward adopting mainstream financial engineering methods and argumentation on asset-valuation methodology are flawed. In order to bring this point out this paper examines the flaws in the argumentation so presented and develops the alternative approach. Thereby, the strictly epistemological methodology of unity of knowledge (Tawhid) ${ }^{(1)}$, fundamental to any Islamic study of issues and problems, is upheld. This premise is then launched to argue against the mainstream financial engineering argumentation and its prevalent acceptance by Islamic economic and financial experts. The paper thus emanates from the stage of presenting salient features of the mainstream financial engineering approach that is found to be centered on risk-return analysis and cash-flow discounting of assets. It then goes into the epistemological formulation of the proposed overlapping generation model. Accordingly, the problem of time-value of money is rejected in the alternative Islamic model of asset-valuation. A cursory quantitative exploration is conducted.

The paper is in the following parts:

(1) From the very outset it should be known that this paper does not deal with the ontological theme of Tawhid as Oneness of Allah, including in it the beatific names of the Lord (Asma al-Husna), the attributes of Allah (sifat), the ultimate predetermination of human fortunes (al-Qadr), and the impossible explanation of the Oneness as in the Mother of the Book (Lawh Mahfuz). It is impossible to cover all the attributes of Allah in describing the worldsystem. Hence only the overarching topological formalism is pertinent to the epistemological issue at point. The Qur'an points out that no fair estimate of Allah can be obtained, except to study his creation in the light of Allah's Oneness as inherent in the divine law expressing this oneness through the Signs of Allah. In the light of the Qur'anic guidance such ontological qualities lie beyond human explanation. Allah's Oneness is to be understood by learning across the domain of the Signs of Allah (ayat) by the principle of unity (pairing) and an everincreasing learning of re-origination (khalq Jadid). This is the inexorable experience in self with the external world (phenomenology = consciousness). Thus Tawhid is inculcated in the Tawhidi Law of Unity as oneness of being of the living experience. This is the fundamental premise of the Tawhidi oneness or unity of knowledge and of the world-systems and of their entities in the good things. It is also revealed in the unity by differentiation, conflict and competition between the bad things (see another footnote in this paper on this idea of Truth and Falsehood) according to the Qur'anic premise explained by topological analytics. Unity of knowledge and being is thus erected on the epistemological premise of the divine law (sunnat Allah), which is unraveled for the self and external relational learning experience by the medium of the Sunnah of the Prophet Muhammad. The Qur'anic knowledge together with the Prophetic guidance are now termed as the fundamental epistemology that evolves the laws and gives it forms (as in Qur'an, Chapter 59:24). Present-day philosophers of science name such a methodology of constructing the logical formalism to explain fundamental functional relations as engineering ontology (Gruber, 1993) as opposed to the metaphysical ontology of Heidegger and Hofstadter (1988). 
Part 1 deals with an exposition of the salient features of mainstream financial engineering issues. The central point of risk-return analysis and interest-driven argumentation is shown to arise from the conformable preference, market and institutional ramifications of such argumentation in mainstream financial engineering. All these are premised on the epistemology of mainstream neo-liberal and neoclassical worldview. The epistemology is reinforced by the consequences of interest-driven interrelations between preferences, socioeconomics and institutionalism, all centered in rationalism and the doctrine of rational choice.

Part 2 emanates from the summary of mainstream financial engineering and the contrary presentation of the Islamic one. This section formulates the Islamic epistemological methodology and constructs the asset-valuation approach on the basis of this epistemological worldview of systemic unity of knowledge as the worldly representation of Tawhid (oneness of the divine law) in muamalat (worldly affairs).

Part 3 formulates the overlapping generation asset-valuation model in the light of the Islamic epistemological background of unity of knowledge. Accordingly, a critique of the time-value of money in discounting future cashflows is launched.

Part 4 is a cursory presentation of a possible parameterization of the model of asset-valuation constructed on the basis of the Islamic epistemological worldview. This section also contains the implications in economic and financial feasibility approach that arise from the ethical consequences of the model of asset-valuation of the Islamic epistemological genre.

Part 5 is a conclusion. A suggestion is made on having the overlapping model of asset-valuation of the TSR genre computerized for use in academia and Islamic financial outlets.

\section{Part 1 \\ A Review of Mainstream Financial Engineering Issues}

\section{Financial Engineering}

Financial engineering is a branch of engineering economics using the tools of interest-based asset-valuation techniques to establish the market-share and optimization models of financial firms. The characteristics of financial engineering garner the methods of risk-return analysis and develop instruments that are based on economic competition and interest-rate regimes of financial markets. Asset-valuation is then molded in the framework of competing firms pitted in rivalry with each other for gaining market shares while each such financial firm solves the risk-return problem of assets within a principal-agent game. 
Yet all models, financial or other, are abstractions of the world as wished for. In the case of financial engineering the rivaling financial domain can be seen as being embedded in individual behavior, markets and institutions including firms, regulatory and government agencies. But in every case, the embedding between these is centered on assumptions upon which financial engineering stands as an explanatory mechanism to carry through the pervasively competitive and self-interest optimization postulates of human and institutional actions as so perceived.

In the end, the postulate of economic rationality delineates the regimes of market competition, scarcity of resources, objective criterion of optimization, and the congruent meaning of steady-state equilibrium of optimal resource allocation. The result is a pervasive presence of the neoclassical postulate of marginal rate of substitution underlying all these consequences. Three specific models of financial engineering are investigated to bring out the embedded nature of the above-mentioned characteristics of economic and financial reasoning.

The end result shows that all of these characteristics hinge on the following central criterion of financial engineering models: the modeling of risk-return analysis in futures markets, and asset-valuation under this condition using discounting methods, which is stated in different forms of the futures models.

Why is our claim on the above-mentioned characteristics a correct one? Let us venture for an answer.

\section{Risk-Return Analysis of Futures as a Central Issue in Mainstream Financial Engineering}

Risk and return analysis assumes that there are two competing sectors of the economy. One is the financial sector where risk abounds; the other is the real sector where return abounds. In the usual neoclassical two sector analysis of financial resource allocation between the two sectors, the assumptions of scarcity, competition, expected utility optimization in risk and return, and steady-state equilibrium are logical consequences. Social and ethical factors are not considered in such asset-valuation and its underlying resource allocation problem.

The intertemporal utility optimization resulting in investor's indifference curves in risk and return, and thereby the intertemporal resource line, yield the valuation of risk and return in terms of the relative prices of risk (interest rate) to return (real rate of return). Marginal rate of substitution now thoroughly underlies this optimization-equilibrium technical problem of resource allocation between the two sectors. But importantly, underlying this marginalist perception, though not socioeconomic reality, is the postulate of rational choice, 
according to which indifference curves are exogenously defined. Consequently, a predictive behavior is assumed to prevail unchangeably. That is, individual savers and institutional investors are assumed to behave rationally by allocating their budgets between competing financial and real sectors. Savers thus pursue saving habit in the financial sector, which bears interest rate, and is thereby differentiated from real sector returns. For the analytical foundation of riskreturn analysis, see Jean (1970).

In risk-return analysis the principal-agent game confirms that the marginal rate of substitution of the two-sector consequences, namely risk and return, also defines the nature of agent-specific expected utility function. This implies that the agent-specific preferences are linearly summed over the principal-specific preferences (Salvatore, 2004). But the implication is deeper for both financial and real sector asset-valuation. It means that the same discount rate prevails for both the agent and the principal. The assumption therefore is that identical perceptions prevail on rational choice behavior for the agent and the principal.

Furthermore, since an agent represents a firm, corporation, conglomerate and also the government as in the case of government bond management, the principal-agent behavior and formalism are extended to the institutional level as well. This is the well-known result of the linear aggregate form of utility function (Hammond, 1989; Harsanyi, 1955). The worsening fact is that social norms as ethics when introduced in such utility aggregation, they trade-off ethics from efficiency as two marginal substitutes. The role of ethics in agent preferences is exogenously introduced so as to impact on the relevant socioeconomic variable. For example, risk-diversification requires agent and government to shelter the principal's assets by interest-rate mechanism. This is tied to monetary policy enacted by the central bank as an exogenous means of attaining systemic risk-diversification and within it consumer protection.

Contrarily, we will argue that risk-diversification and selection of instruments to protect the consumer is a combination of market function and good management. Both of these are formed by principal-agent reactive learning. Then the use of appropriate real-sector instruments mobilizes funds towards attaining ethics and efficiency as complementary goals.

\section{The Role of Epistemology Underlying Financial Engineering Assumptions}

We have now explained three causal levels of interaction that work both for mainstream and Islamic economic and finance cases. The schema for mainstream economics and finance is shown in Fig. 1. It is important to note here the circular causation processes that are continuously generated in this schema between preferences, markets (socioeconomics) and institutions, shown by arrows. Later on, the same kind of schema will assume a different meaning in the case of Islamic economics and finance of asset-valuation. 


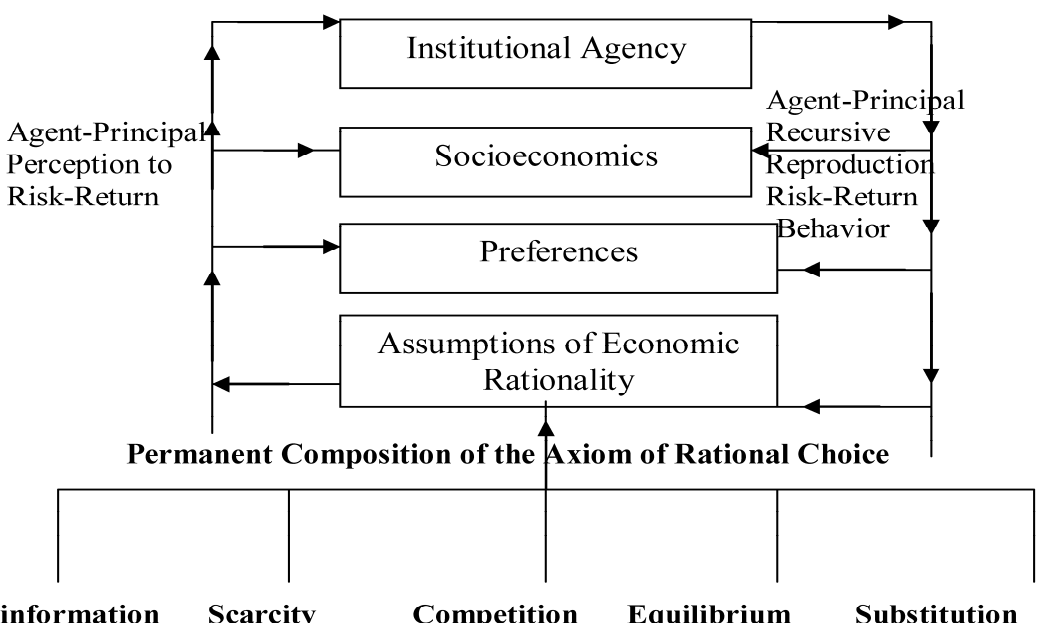

Full-information Scarcity

Competition

Equilibrium

Substitution

Fig. 1. Schema for Preference, Socioeconomics and Institutional Complementarities in the Case of Economic Rationality involving Risk-Return Behavior.

Every scientific idea and belief system is driven by a foundational epistemology. In the neo-liberal and neoclassical paradigms, the economic, social, institutional and scientific beliefs and methodology rest upon the premise of rationalism. From rationalism are derived specific postulates, such as social Darwinism of mutated competition for natural selection in social system, economic rationality in economics and finance, logical positivism in science. Fig. 1 points out that there are reinforcing interrelationships between the foundational axiom and different parts of the socioeconomic and institutional order. But the basis of such interrelationships is to know how the belief mechanism presents the world-system to the specific beholder. Upon the consequential elements of the foundational axiom of rationalism and its derivative, rational choice in economics and finance color the epistemological foundation of neo-liberal and neoclassical reasoning.

The interrelationships shown by arrows in Fig. 1 arise from such an episteme and establish a pervasive system of competition, acceptance of resource scarcity and self-interest premised on winner-take-all mentality. The latter postulate is further signified by the neoclassical and neo-liberal beliefs on the optimal individual and the analytical result of steady-state equilibrium. Upon these are developed the economic and financial world-system addressed by financial engineering models, behavior and instruments. Methodological individualism and its replication in socioeconomics and institutions thoroughly wash such epistemological beliefs.

According to such epistemological viewpoint, the objective criterion of neoliberalism and neoclassicism is the expected utility maximization with risk and 
return analysis of future outcomes. The whole genre of financial engineering models that arise from such a foundational belief constructs a world-system of mutual conflict, trade-off and uncertainty due to predator egos. Underlying these is the functioning of the technique known as marginal rate of substitution. This becomes a natural corollary of the axiom of rational choice vis-à-vis rationalism. It is a solely human construct abandoning any primal reference to ethics, morality and denying the place of higher authority above rationalism and methodological individualism (von Mises, 1976). Thus, God and the divine law, even if taken in their most logical sense, are denied in the face of methodological individualism and its socioeconomic and institutional transcription. This is the methodological implication of the schema shown in Fig. 1.

Yet such a transcription is far from truth and, at best, a laboratory experimentation of hegemony and power for control and governance. Later on in this paper we will show that the same Fig. 1 cast in the Islamic meaning presents an opposite worldview according to unity of knowledge emanating from the Quranic epistemology. Thus the Islamic epistemological methodology will present a contrary model of asset-valuation, all together different from the mainstream financial engineering approach and perspective.

\section{Principal Issues of Financial Engineering}

It is the objective of this section only to summarize the principal financial instruments in mainstream finance so as to bring them to the level of critical examination in the light of Islamic financing instruments and to propound these alternative ones. It is not the objective here to elaborate on any of the mainstream instruments.

\section{Futures}

In financial engineering, futures establish claims on uncertain cash-flows. Consequently, the agent manages funds with financial instruments and protection of the principal's expected utility function by changing the portfolio composition that is aimed at arresting risk and promise returns. All this is good intention.

However, the modes of attaining these conditions are based on risk-return trade-off as explained above in the case of the finance and real economy twosector competing model of resource allocation. The result is trade-off of resources between the real sector and financial sector and vice-versa. The two sectors thus get automatically segmented and competing. The enticement for such marginal substitution of resources between the financial and real sectors is driven by the price relative (interest rate/real rate of return). 
Some of the financing methods that the agent exercises to protect the cashflows of the principal are options, derivatives, hedging. But as we will see now, these very methods are risk-creating or not risk-avoiding.

\section{Options}

Consider the Call Option or Call Price C(S,E,t), that depends on the Stock Price (S), the Exercise Price (E) and expiration time (t). The value of $\mathrm{C}($. depends upon how $\mathrm{S}$ and $\mathrm{E}$ move relative to each other, causing the option at one time to become a Put Option (sell a good) and at another time a Call Option (buy a good) (Kolb, 1994). But both S and $\mathrm{E}$ are estimated under conditions of uncertainty, which is measured by probability measures of future variances of prospects. The expected values of S and E (prospects) are based on the agent's perceptions on risk and return. This in turn depends on the (interest rate/real rate) price-relative. The matter was explained above.

\section{Hedge}

In order to maintain a positive value of the Call Option a Hedge restructures risk by trying to keep E $>$ S. Consequently, the Present Value of $\mathrm{E}$ is maintained above the Present Value of S. If the two Present Values are equal a Call Option will turn into a Put Option and a transaction between buying (Call) and selling (Put) is exercised. The resulting terminal price of the Option is the Expiration Price. Yet $\mathrm{S}$ and $\mathrm{E}$ remain uncertain in futures. So also do their Present Values. Therefore, to compensate for such uncontrollable risk caused by financial volatility, the financial sector must give the incentive of higher interest rates, really of term structure of interest rates, to the saver. This fact is also explained by uncontrollability of the Hedge Ratio when financial markets are ridden by volatility. It then becomes difficult to maintain predictable covariance value between present (spot) and future prices (speculative). The risk-return issue is once again confronted with protecting the saver with higher interest rates, and thereby, the investor with lower real rate of return. Marginal rates of substitution abide.

\section{Speculation}

The uncertainty surrounding hedged futures causes speculation to enter the financial scene. Speculators reap profits under such uncertain future conditions. They move funds between the real sector and the financial sector according to their perceptions of profits to be earned on portfolio mixes that they hold. Financial engineering in this case provides the speculator with the tool of riskreturn analysis with appropriate future discounting and the kinds of risk-averse investors in the market. These vary from low to high risk-avert investors. The elements of such technical analysis lead the speculators and the hedge managers to estimate risk premiums as the rate of return in risky assets in terms of the yields in the portfolio. The market portfolio is inevitably interest-driven (Friedman, 1989). 


\section{Debt (Bond)}

Options, hedging, and speculation in futures always involve the construction of a portfolio to perform the principal-agent financial contract. Such a portfolio is hemmed in by interest-yielding assets. The valuation of the portfolio inevitably involves the valuation of short term interest-yielding assets. On the other hand, in the case of real assets a trade-off is generated between the financial portfolio and the real sector portfolio. This is the perennial game of risk-return analysis in financial engineering (Tobin, 1958).

Among the kinds of instruments held in the financial portfolio is bond. Bonds of all kinds are debt instruments. In the case of private bonds, riskaversion remains high. In the case of government bonds risk-neutrality prevails. But financial engineering methods equally apply the present-valuation method despite higher or lower discount rates for the two kinds of bonds, respectively.

Debt financing by bond issuance is a way of financing projects by public money in the case of excess demand for funds to finance projects. The bondholder is guaranteed a rate of interest as premium against uncertainty of futures. In the case of private bonds the differential gains of the premium over portfolio rates fluctuate. Hence options, hedging and speculation are needed to generate the premium surplus. In the case of government bonds, the risk is absorbed by government as agent. Governments are risk-neutral agents. Consequently, government bonds finance debts that may be unproductive, and hence harmful, by creating systematic risk in the economy as a whole. In either case thereby, bonds as debt instruments are linked with either risky or inefficient financing of projects.

The central role of risk-return behavior in debt-financing of assets by bonds is thereby evident. On the side of risk-management, financial engineering is predominant on aiming at financial sector efficiency. On the side of the real economy, government absorption of risk to finance uncertain projects results in inefficient debt-financing. Between private and governments bonds the efficiency and equity trade-off of investor's financial resource allocation is once again manifest.

\section{Summary of Part I}

From our above review of the salient features of financial engineering and the nature of uncertainty that it wants to tackle, we note that risk-return behavior is endemic to the recursively driven relationships shown in Fig. 1. The most important inference we draw is the need for a structural reversal of Fig. 1 into complementary relationships between the financial and real sectors. The resultant analytics give an altogether different understanding of the risk-return relationship in the presence of financial-real economy complementarities. The 
financial engineering models thereby change completely. In the case of the Islamic alternative, the mainstream financial engineering arguments and applications must be thoroughly revamped. Such an extensive transformation emanates from Islamic epistemological foundation, just as rationalism and economic rationality define the epistemological outlook of neo-liberalism and neoclassicism. We examine this second part of the paper next.

\section{Part 2 \\ Islamic Asset-valuation Perspectives: Epistemological Questions and Theory}

For quite some time now the method of valuation of assets in Shariah perspectives has remained elusive to Islamic economists and financial experts, who principally work in the milieu of present-value, cost-benefit modeling and all that go with these. Consequently, much of the premises of mainstream financial engineering have been accepted by Islamic economists and financial experts. El-Gamal (May 23, 2007) discards the riba (interest rate) argument in Islamic financing. He writes, "Irrational adherence to outdated medieval jurisprudence [and] supports the development of a separatist and boastful Islamic identity".

In the case of cash-flow discounting, which plays the central role in riskreturn allocation according to the neoclassical marginal substitution doctrine, the argument presented is that debt is permissible if agreed upon between the lesser and the lessee. The argument made is that the forward contract between buyers and sellers, and hence between Islamic banks and clientele in drawing up a forward delivery contract, can be priced at the present time against the expectation of cash-flows in future time using analysis based on utility function (Ebrahim \& Bashir, 1999; Khan, 1996). The financial instruments of ijarah (rent), bay '-mu'ajjal (forward contracts) and al-dayn (debt) are made to operate on the basis of this groundwork of a sheer popular fiqh understanding of forward contracts, whereas not delving fresh into the Qur'an and the Sunnah for new intellectual insight. The Quran and the Sunnah and not the fiqh, as the principal origin, comprise the true source of Islamic epistemology in everything. That is where we begin the Islamic world-system. In this paper the part of the Islamic world-system is particularized to economic and financial issues.

The Qur'anic epistemology of unity of divine knowledge (Tawhid) manifests itself in systemic learning dynamics by the principle of pervasive complementarities between the good things of life (Quran, 20:81). This reflects the pairing dynamics of the Qur'anic universe. It signifies the Signs of Allah (Qur'an, 36:36) in studying purpose, balance and wellbeing (Qur'an 36:37-42). The principle of pervasive complementarities between the good things of life is 
a unique and universal principle arising from the Qur'an. Pairing between the good things of life represents learning by systemic interaction, integration and creative evolution (Choudhury, 2006a) in the domain of good things of life. The increasing enjoyment of the fruits of such learning by pairing between the good things of life is measured by the wellbeing criterion (Qur'an, 14:24-25, 27).

The Wellbeing Objective Criterion is opposed to the entire genre of utilitarian analysis on which also hinges the economic welfare concept as gaining upon trade-offs by rivalry. This was explained earlier in the context of the rationalist origins of neo-liberalism and neoclassicism. The Quran treats rationalism as falsehood, the source of human ego and human destruction (Qur'an 14: 26). Imam al-Ghazali (Ghazali trans. Marmura, 1997) wrote powerfully against rationalism as being contrary to truth.

The principle of pervasive complementarities between the good things of life in the sense of learning by systemic interrelations between them is the surest representation of unity of knowledge in the manifest world of Signs of Allah. It is unique and universal by virtue of being contrary to the postulate of marginal rate of substitution. This latter postulate is entrenched in all of western socioscientific reasoning. Besides, the singular nature of oneness in the case of the pairing Qur'anic universe is represented by its reality in the world-systems that perpetually learns by the processes of unification. The learning and unification contexts of unity of divine knowledge that projects on to all issues and problems under investigation is indeed the moral foundation of worldly affairs (muamalat) (Choudhury, 2006b).

Before particularizing the principle of pervasive complementarities to the case of financial engineering in the Islamic context, we re-investigate Fig. 1 in light of the Qur'anic epistemology of unity of knowledge (Tawhid) in our world-systems. Figure 1 is reproduced in Fig. 2 with the relevant Tawhidi consequences of learning in pairs.

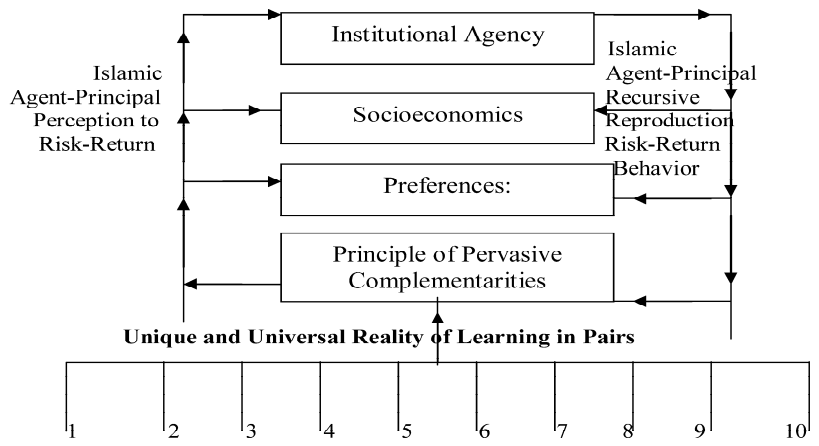

Fig. 2. Schema for Preference, Socioeconomics and Institutional Complementarities in the Case of Unity of Knowledge (Tawhid). 
The numbered points are explained below and the relational epistemology is established in expression (1) in terms of what is termed as the Tawhidi String Relation (TSR).

\section{The Tawhidi String Relation (TSR): The Epistemology of Unity of Knowledge by the Topological Formulation ${ }^{(2)}$}

In Fig. 2 the following symbols are defined. Follow the numbers in Fig. 2:

1. Tawhid $\Omega$ denotes the supercardinal topology of the absolute divine law (Rucker, 1982). It explains everything in the most perspicuous of ways. Thus the Qur'an along with the Sunnah unravels the model of Truth and Falsehood

(2) Why a topological, and thus mathematical approach to the Tawhidi epistemological critique of financial engineering in mainstream theory? In answer to this question the following important issues need to be understood.

Firstly, topological methods involve mathematical sets of dimensionless and non-forms relations and entity abstractions. This is the most proper way of studying the dimensionless episteme of Allah's knowledge, which is complete and absolute. Thus the precept of Supercardinal Topology is applied to the primal episteme topology. See my definition of topology, topological mapping and topological space in the paper. Also refer to my explanation of the epistemic precept of Supercardinal Topology in the sense of completeness and absoluteness of the divine law. From the idea of Supercardinal Topology is derived the relational domain of the space of Truth statements and False statements, the subsets within the primal space of Tawhidi unity of knowledge, the superspace. My definition of Supercardinal Topology comprises firstly $\Omega$ as the Complete and Absolute Domain of the Qur'anic Law of Oneness as expressed in the sense of the Tawhidi unity of knowledge and of being in the world-systems. From these primal facts are derived the worldly entity-relationships. The second part and parcel of $\Omega$ is the career of the divine law, which is contrary to human rationality and rationalism. This is the medium of transmission of the comprehensible part of $\Omega$ for the formation of knowledge-flows and their induced entity-beings of the world-systems. Thus arises the idea of the Shari'ah (Islamic Law) and muamalat (worldly matters) as knowledge-induced law and affairs for the living experience. S (the Sunnah of the Prophet) being the enabling mapping of $\Omega$, the fundamental epistemology is denoted by $(\Omega, \mathrm{S})$.

Secondly, does this mesh up the exclusive identities of $\Omega$ and $\mathrm{S}$, as if Qur'anic revelation can be meshed up with Shakespearean plays? This is never the case, for while topology allows for the absolving of identities in its sets of things, the topological sets, mappings and spaces equally apply to the separate identities, and yet the abstraction in such identified subsets is preserved. Hence is our characterization of Truth and Falsehood in footnote 2.

Thirdly, why is it necessary to utilize mathematical formalism in terms of topological analytics? This is because mathematics is a language of precision of the explained, and thereby, of the world-systems induced by topological mapping starting from $(\Omega, S)$ and carried through by worldly rule forming relations (ahkam) derived always from $(\Omega, \mathrm{S})$. The logical and analytical language precision is conveyed by mathematics as one of mankind's great gifts, the worldly understanding of signs of Allah (ayat). The Lucasian Professor of Mathematics at Oxford University remarked in his book The Emperor's New Mind that great works of arts and the sciences are nearer to God than the smaller ones. 
both. But the rationalist doctrine cannot explain the Qur'anic Truth statement and hence not the Tawhidi worldview ${ }^{(3)}$.

2. Sunnah $\mathrm{S}$ denotes the medium of the Prophet in transmitting 'bits' of $\Omega$ into the world-system. Thus, $(\Omega, S)$ is the tuplet that defines the entire Tawhidi supercardinal topology.

3. Step (3) denotes the mapping of 'bits' of $\Omega$ by $S$, that is $(\Omega, S)$, into the domain of acquired knowledge formation. The mappings denoted by functions (not shown but indicated by arrows) appear as rules derived from the Quran by Sunnah. Such knowledge formation is denoted by ' $\theta$ ' as the consensual value of discoursed knowledge-flows in the shura as a learning process. Thus $(\Omega, S) \rightarrow \theta$.

4. The instantaneity between knowledge and observation through relational learning between the two is characteristic of socioeconomic values in the worldsystem. These are denoted by the vector $\mathbf{x}(\theta)$ as the list of variables that are endogenously embedded by $\theta$-values. We denote the limiting knowledgeinduced tuplet by $(\theta, \mathbf{x}(\theta))$. Thus we derive the meaning of causality on the

(3) On the matter of Truth and Falsehood as engineering ontological statements in the light of the Tawhidi worldview here is a topological formalism:

We prove here the following theorem.

The episteme of unity of knowledge represented by pervasive systemic complementarities is both unique and universal in explaining the nature of Systemic Unity and Methodological Individualism. Contrarily, the model of Methodological Individualism cannot explain the worldview of unity of knowledge.

I. Let $\{\theta\} \in\left(\Omega^{\mathrm{T}}, \mathrm{S}^{\mathrm{T}}\right) \subset(\Omega, \mathrm{S})$ for systems, $\mathrm{s}=1,2, \ldots, \mathrm{N}$. T denotes the system of wellbeing entities. But both complementarities of wellbeing and methodological individualism are comprised in $(\Omega, S)$.

$\Rightarrow \quad \cup_{\text {interaction }}\{\mathbf{x}(\theta), \theta\} \subset\left(\Omega^{\mathrm{T}}, \mathrm{S}^{\mathrm{T}}\right)$; the interactive or diversity condition;

$\cap_{\text {integration }}\{\mathbf{x}(\theta), \theta\} \neq \phi \subset\left(\Omega^{\mathrm{T}}, \mathrm{S}^{\mathrm{T}}\right)$, the integrative condition,

$\cup_{\text {interaction }} \cap_{\text {integration }}\{\mathbf{x}(\theta), \theta\} \neq \phi \subset\left(\Omega^{\mathrm{T}}, \mathrm{S}^{\mathrm{T}}\right)$, interactive and integrative condition

These are the properties of subsets belonging to $(\Omega, S)$, which because it is denumerable and non-dimensional, forms a superspace (Rucker, 1983).

II. Because of methodological individualism in Falsehood domain,

$\cup_{\text {interaction }} \cap_{\text {integration }}\{\mathrm{x} \sim(\theta \sim), \theta \sim\}=\phi \subset(\Omega \sim, \mathrm{S} \sim) \subset(\Omega, S)$ as Falsehood facts.

Since these facts form a superspace within $(\Omega, S)$, we denote it by $\left(\Omega^{\mathrm{T}}, \mathrm{S}^{\mathrm{T}}\right)$, such that, $(\Omega \sim, \mathrm{S} \sim) \cap\left(\Omega^{\mathrm{T}}, \mathrm{S}^{\mathrm{T}}\right)=\phi$; and $(\Omega \sim, \mathrm{S} \sim) \cup\left(\Omega^{\mathrm{T}}, \mathrm{S}^{\mathrm{T}}\right)=(\Omega, \mathrm{S})$.

Because $\{\mathbf{x} \sim(\theta \sim), \theta \sim\} \in(\Omega \sim, S \sim)$ and $\{\mathbf{x}(\theta), \theta\} \in(\Omega, S)$, therefore,

$\{\mathbf{x}(\theta), \theta\} \cup\{\mathbf{x} \sim(\theta \sim), \theta \sim\} \in\left(\Omega^{\mathrm{T}}, \mathrm{S}^{\mathrm{T}}\right) \cup(\Omega \sim, \mathrm{S} \sim)=(\Omega, \mathrm{S})$

Therefore, $(\Omega, S)$ explains both truth and falsehood facts.

III. Contrarily, starting from $(\Omega \sim, S \sim)$ primordially yields,

$\cup_{\text {interaction }} \cap_{\text {integration }}\{\mathrm{x} \sim(\theta \sim), \theta \sim\}=\phi \notin\left(\Omega^{\mathrm{T}}, \mathrm{S}^{\mathrm{T}}\right)$ but $\phi \in(\Omega \sim, \mathrm{S} \sim)$.

Therefore, neither $\left(\Omega^{\mathrm{T}}, \mathrm{S}^{\mathrm{T}}\right)$ nor $(\Omega \sim, \mathrm{S} \sim)$ can explain total reality. Only $(\Omega, S)$ explains total reality.

Consequently, $(\Omega, S)$ is universal in explaining 'everything'.

$(\Omega, S)$ is unique because neither $\left(\Omega^{\mathrm{T}}, \mathrm{S}^{\mathrm{T}}\right)$ nor $(\Omega \sim, \mathrm{S} \sim)$ by themselves can explain total reality. 
basis of the principles of unity of knowledge derived from the chain of relationship, $(\Omega, \mathrm{S}):(\Omega, \mathrm{S}) \rightarrow \theta \rightarrow \mathbf{x}(\theta)$.

It is important to note here how $(\theta, \mathbf{x}(\theta))$ are formed out of preferences denoted by $\wp(\theta \in(\Omega, S))$. Preferences are carriers of $(\theta, \mathbf{x}(\theta))$, because they spring from the belief system that is governed by learning and abidance by Qur'anic rules and guidance $(\theta)$. The tuplet is then extended as $(\theta, \mathbf{x}(\theta) ; \wp(\theta \in$ $(\Omega, S))$.

Note also the specific characteristics of knowledge formation in the shuratic process of learning by pairing, i.e. recognizing the principle of pervasive complementarities between the good things of life. The discursive process of knowledge formation in the shura taken in its extensive sense of organic participatory dynamics in everything (e.g. recognizing tasbih, moral consciousness, in the socioeconomic system), goes through interaction leading to consensus (integration) on the basis of rules and guidance derived from the Quran on specific issues under investigation.

5. The process formation: $(\Omega, S) \rightarrow \theta \rightarrow \mathbf{x}(\theta)$

$\downarrow(\theta, \mathbf{x}(\theta))$ leads to simulation of Wellbeing

The Wellbeing Objective Criterion denoted by $\mathrm{W}(\theta, \mathbf{x}(\theta))$ is defined as the measure of unity of knowledge attained during a process of learning in the world-system out of the application of the rules derived from $\theta$ in the light of $(\Omega, S)$. The pairing as unity of knowledge is denoted by circular causation (symbiosis) between the elements of the vector $\mathbf{x}(\theta)$, each one in terms of the other ones taken up in non-linear structural equations. There are also the new $\theta$ values read off at the end of the processes post-evaluation by means of the following simulation exercise:

Simulate $\left.{ }_{(\theta, \mathbf{x}(\theta))} \mathrm{W}(\theta, \mathbf{x}(\theta))\right)$, subject to circular causation between the $\mathbf{x}(\theta)$ values by non-linear structural equations, and the re-setting of $\theta_{\text {new }}$-value that becomes emergent at the end of a simulation process (Choudhury, 2006c).

6. Step (6) is the starting point of co-evolution of the ending process into a new process of learning. In Step (6), Interactions have actualized into Integration and these two states have led to co-Evolution. We call this whole learning process as being endowed by the IIE-characteristics. IIE characterizes appear in every part of the TSR as intrinsic learning properties.

7. Step (7) is the start of the second (new) process. The attained learning process up to this point is denoted by,

$(\Omega, S) \rightarrow \theta \rightarrow \mathbf{x}(\theta)$ 


$$
\downarrow(\theta, \mathbf{x}(\theta)) \rightarrow \operatorname{Simulate}_{(\theta, \mathbf{x}(\theta))} \mathrm{W}((\theta, \mathbf{x}(\theta))
$$

\section{s.t. circular causation between $\mathbf{x}(\theta)$-values}

\section{$\downarrow$ Co-Evolution to $\theta_{\text {new }}$}

8. In Step (7) the learning process continues on in simulation stages of learning in the paired universe of the $(\theta, \mathbf{x}(\theta), \mathrm{W}((\theta, \mathbf{x}(\theta)) ; \wp(\theta \in(\Omega, S)))$ values. The importance of preferences and the interactive role of socioeconomics system $\mathbf{x}($.$) together with institutional (policy, structural and$ instrumental effects of learning modes) $(\theta)$ are combined with the engineering approach of simulation of wellbeing index with circular causation relations. The circular causation relations are reflective of pairing between the variables and the use of new rounds of $\theta$-values to improve the simulated levels of complementarities between the good things of life, namely between the elements of $\mathbf{x}(\theta)$.

9. Step (9) shows the continuation of the TSR until the Event of the Hereafter (Akhirah). Since the Hereafter is characterized as the Great Event in the Quran (Chap. 78), therefore, its attainment means the self-actualizations of all the world-systems ('alamin) through Tawhid. We now have the completed TSR: ${ }^{(4)}$

(4) Mathematics though logically precise, which is a Qur'anic fact, is not complete. The latter too is a Qur'anic fact (See A.Y. Ali, footnote 5673 of Qur'an, 69:51). In this respect, Godel's incompleteness theorem of arithmetic is explained in this paper by the perpetual and incomplete process of learning on unity of knowledge. This paper too denies the completeness of truth statements to mathematics. It simply treats mathematics as a relatively most precise form of logical formalism. While treating the Tawhidi knowledge-induced world-system by its methodology, this paper established the fact that mathematics is incomplete in the learning domain of endless regress. Thus no tautology exists in the mathematical formulation of the Tawhidi complete process-based learning formalism explained in this paper, with the worldsystem being in between Tawhid and the Akhirah (the Hereafter).

Note in this regard the following theorem that emerges from this paper:

Godel-Tarski sentences in provable and non-provable truth and false statements

In Gödel and Tarski's theorems on the incompleteness of arithmetical systems (Gödel, 1965; Smullyan, 1992), the string $P N(X)$, and its mathematical complementation (opposite) $\sim P N(X)$, denote sentences. Sentences are meaningful relations between subjects and predicates. This means that either (1) the norm of a statement $X$ denoted by $N(X)$, is provable $(P N(X))$, or (2) such an $N(X)$ is not provable, denoted by $\sim P N(X)$.

The norm of a statement $X$ by itself (self-referencing) is defined by $X(X)$.

On the other hand, the string $P(X)$ means the provability merely of $X$ itself. Thus if $P(X)$ is found to be true, then $X$ would be true. However, if $X$ is true, it is not necessary that $P(X)$ will be Godelian true, since $P(X)$ may not belong to the set of all provable statements.

The same implications hold for $\sim P(X)$. i.e.

$P(X) \Rightarrow X$ but $X$ being a truth does not necessarily suggest $P(X)$ 
Likewise,

$\sim X \Rightarrow \sim P(X)$ but $\sim P(X)$ being true does not necessarily mean $X$ is not true

An example here is this: 'To tell lies is sinful'. But this $X$-truth statement is not provable, as in the case of the Liar's Paradox. Thus, although the moral standard of the statement is abiding truth, yet it is Godel non-provable.

In the case of $P N(X)$ and $\sim P N(X)$ for Godel's incompleteness theorem, we note the strong implications that the expression $X$ refers to itself. That is, $X(X)=X$ and $\sim X(\sim X)=\sim X$. That is, the truth-statement, say $X$, self-references; the false-statement, say $\sim X$, self-references.

But it is not true that $P(\sim X)=\sim P(X)$, meaning that provability of a false-statement does not imply the non-provability of a true-statement and vice-versa. An example is this: the boy who is a compulsive liar cried 'Wolf' on his flock of sheep. People disbelieved the statement as lie $(\sim X)$; but the wolf did come down on the flock of sheep, $X$. Thus the non-provability' of a true statement (wolf did come down) $\sim P(X)$ ), was not provability of a false-statement (compulsive lying, $P(\sim X))$.

Likewise, according to Godel-Tarski theorems the following are not universally true:

$P(X)=P N(X) ; \sim P(X)=\sim P N(X)$

That is because the total domain of $N(X)$ may not be provable in terms of $X$. Likewise for the case of non-provability of $\sim X$. There is undecidability here.

\section{Rejecting Godel-Tarski sentences by the Quran}

The above kinds of sentences dealt with in Godel-Tarski incompleteness theorem are absurd in Qur'anic terms on grounds of the universality of the Tawhidi epistemology (oneness of God) and the emanating guidance and laws. The Qur'anic laws and guidance emanate in the ontological sense.

Let us see.

It must be true that $P(\sim X)=P N(\sim X)$. That is, the provability of a false statement means the provability of its norm. In the Tawhidi epistemological context, the concept of norm refers to the confirmation of belief (likewise, disbelief) in divine unity as the totality of universally provable statements of truth and of falsehood over all kinds of statements on specific matters.

Likewise, according to the Qur'an $P(X)=P N(X) ; \sim P(X)=\sim P N(X)$.

A 'sentence' is thus defined in any of the following forms: (i) $P(X)$, (ii) $P N(X)$, (iii) $\sim P(X)$, (iv) $\sim P N(X)$.

Self-referencing as we have defined it in the context of its necessary and sufficient condition of universality of the Tawhidi worldview must imply, $P(X)=P N(X) ; \sim P(X)=\sim P N(X) ; P(\sim X)$ $=P N(\sim X) ; \sim P(\sim X)=\sim P N(\sim X)$. That is, a true statement is provable if and only if its norm is also provable.

Take back our example of the liar. The boy calls 'Wolf'. According to Islamic law and guidance, it is the responsibility of the community to attend to his call, despite that this may be proven to be a false statement. But as the Tawhidi responsibility increases in the boy through knowledge-induction (guidance), the statement comes nearer to provability. Then, $P(X) \approx P N(X)$. This is the case of transformation into Tawhidi responsibility by Islamic knowledge-induction (tarbiah). Likewise, $\sim P(X) \approx \sim P N(X)$ is the case of rejection of Tawhidi transformation as falsehood, as in the case of a well-determined compulsive liar. 
In Qur'anic terms, we refer to the classes of undecidable statements among the unbelievers of divine unity and God's Command as being absurd. Take the Qur'anic verse (Qur'an, 2:210): "Will they wait until God comes to them in canopies of clouds, with angels (in His train) and the question is (thus) settled? But to God do all questions go back (for decision)."

Here both the non-provability of the statement of absurdity $\{\sim P(X)$ and $\sim P N(X)\}$ : "God comes to them ... canopies of clouds ... angels ... questions is (thus) settled", and the confirmation of the statement of truth $\{P(X), P N(X)\}$ :"But to God do all questions ... go back...", are established.

Thus both sets $\{P(X), P N(X)\},\{\sim P(X), \sim P N(X)\}$ are acceptable sentences in the Qur'an. In other words, $P(X)=P N(X)$ [statement of belief] and $\sim P(X)=\sim P N(X)$ [rejection of the statement of unbelievers] are both provable according to the above verse.

The incompleteness of the mathematical method in the context of continuous learning in unity of knowledge and entity-being by the Tawhidi law of unity of the divine law acting on the world-system is a theory embedded in 'everything'. That is because it is the universal law. This paper claims the human quest for that law and its formalization and application to be the final universal quest of mind and matter. Thus the progressive of knowledge and the world in the learning world-system according to the Tawhidi methodology is an ever-unraveling experience. The Qur'anic methodology is indeed of this kind. It is also of the kind that was claimed both by Imam Ghazali (trans. Buchman, 1998) and Ibn al-Arabi (trans. Chittick, 1989). Indeed, unity of the sciences by the uniqueness of methodology has been the timeless quest of scholarship (Barrow, 1991).

It ought to be noted as well that self-referencing is a mathematical logic that banks upon the search for the most reducible premise for explaining 'everything' but with incompleteness of learning as the endowed element in its search. The human quest is thus from Allah to return back to Him in every matter. The Qur'an establishes this kind of self-referencing with respect to the only premise that is complete, while all other domains remain incomplete, both by knowledge (mind) and materiality (matter) (Qur'an, 31:34). Thus only Tawhid as Oneness of Allah and Tawhidi Law as the methodology of unity of divine knowledge and the constructed world-systems remain permanent, but not so the validity of specific statements vis-à-vis issues. These are subject to extensive validation. The Tawhidi world-system thus moves from the Tawhidi episteme of Oneness, i.e. unity of divine knowledge vis-à-vis $(\Omega, S)$ from the Beginning to the End and from the End to the Beginning (Qur'an 92:13).

Hence, by the assumptions of completeness and universality, if $\forall\left(\theta \in \Omega \Rightarrow \Omega \rightarrow_{\mathrm{S}} \mathbf{x}(\theta)\right]$ and also $\forall\left(\theta \in \mathrm{A} \Rightarrow \mathrm{A} \rightarrow_{\mathrm{S}} \mathbf{x}(\theta)\right.$ ], with $\mathrm{A}$ as the topology of the End (Great) Event called Akhirah, then $\Omega=\mathrm{A}$ in the sense of knowledge.

Also since $\Omega \rightarrow_{\mathrm{S}}$ World-System $[\theta \in(\Omega, \mathrm{S})]$; then $\mathrm{A} \rightarrow_{\mathrm{S}}$ World-System $[\theta \in(\Omega, \mathrm{S})]$. Hence, $\Omega \rightarrow_{\mathrm{S}}$ World-System $[\theta \in(\Omega, \mathrm{S})] \rightarrow_{\mathrm{S}}[\Omega=\mathrm{A}]$. The world-system learns and is therefore validated by the episteme of $(\Omega, S)$ in the complete universe $\Omega \Leftrightarrow$ A.

Thus there is no tautology in the Tawhidi formalism as constructed. The Tawhidi methodology is derived from the Qur'anic verses (92:13): “And very unto Us (belong) the End and the Beginning..." and "He (alone) knows the Unseen, nor does He make any one acquainted with His mysteries, -- except an apostle Whom He has chosen..." (Qur'an, 72:226-27).

Furthermore, note the important implication. That is, only the divine laws $(\Omega)$ explained by Smapping is exogenous. Whereas, all knowledge-flows and their induced entities are endogenous in their relations while being exogenously derived from $(\Omega, S)$. Consequently, in 
Process 1

$(\Omega, \mathrm{S}) \rightarrow \theta \rightarrow \mathbf{x}(\theta)$ $\rightarrow$ learning processes $\downarrow(\theta, \mathbf{x}(\theta)) \rightarrow$ Simulate $_{(\theta, \mathbf{x}(\theta))} \mathrm{W}((\theta, \mathbf{x}(\theta))$

s.t. circular causation between $\mathbf{x}(\theta)$-values

$\downarrow$ Evolution to $\theta_{\text {new }}$

$\downarrow$ continuum

of learning

and pairing

processes

$\downarrow$ Hereafter

Expression (1) can assume multidimensional levels (diverse systems) of TSR with IIE defining complementary learning relations between such diverse systems. The Qur'anic Chapter Ra 'd (13: 1-5) and Chapter al-Mu'minun (23:17) bring out such multidimensional dynamics in terms of the cosmos-world relationship and the seven heavens, respectively.

(10) One further step needs to be noted. This is the summarizing of the TSR as a complexity of learning bundles embedded within the totality of worldsystems (a lamin) and their elements. We denote the reduced TSR by,

$$
\Omega \rightarrow_{\mathrm{S}} \text { World-System }\{\theta, \mathbf{x}(\theta)\} \rightarrow \Omega=\text { Akhirah }
$$

The TSR is a closed system yielding evolutionary learning equilibriums but no temporal optimum states while simulation remains pervasive in the midst of learning by pairing as the surest Sign of Allah in unity of the divine laws across the scheme of things. The closure of the TSR signifies the temporality of learning world-systems in the large scale universe (Qur'an, 78:17).

The TSR is a mathematical formulation of many of the ideas that the great scholastic Islamic scholars have bequeathed to the world of learning. It is therefore a part of the Islamic scholarship going beyond a sheer utterance of Tawhid as the cardinal principle of the Islamic worldview ${ }^{(5)}$.

this kind of exogeneity of $(\Omega, S)$ and endogeneity of the knowledge-induced world-system, there can never be an equation of the Divine Law with God. I have explained this point earlier in another footnote.

(5) The foundation of Islamic philosophy of science is indeed the Tawhidi worldview. The Tawhidi methodology, formalized in this paper as a continuously learning experience in unity of knowledge and entity-being over knowledge, space and time structure has in fact been in the minds of the greatest of the Islamic learned scholars (mujtahids). Note the following quotation from Imam Ghazali on continuous learning that enables the mind to come nearest to Allah, that is to understand the Oneness of Allah as we passage through the self and worldly experience: 


\section{The Tawhidi Epistemology Applied to Asset-valuation: The Overlapping Generation Asset-valuation Model}

\section{Contrasting Risk-Return Concepts between Islamic and Mainstream Financial Engineering}

The Islamic context of financial engineering will utilize the Tawhidi epistemological model to lay down the reasoning behind the study of risk and return and thereby asset-valuation. Thus a number of matters need to be explained in reference to Fig. 1 and in the light of Fig. 2.

Firstly, we note how the preference basis of decision-making has changed from the rationalistic individualism of neo-liberal epistemology to the unity of knowledge as the Islamic epistemology. Subsequently, the entire methodology of Islamic resource allocation, perception and management of asset-valuation in the Islamic framework will hinge on the underlying pairing principle of pervasive complementarities between the good things of life. Shortfalls are corrected and the rationalist regime rejected by transformation of human and institutional behavior into unity. The objective at the end is to establish a stable and rewarding wellbeing perspective of economy, finance and monetary embedding. Such a case of complementary linkages reflects the surest and clearest meaning of the Signs of Allah in terms of unity of knowledge. We need

Ghazzali wrote (Karim, (n.d.), p. 240) [edited]: "So is the mistake of one whose breast has not been expanded by the light of God (deep love of Tawhid = kashf) He does not see the ultimate Cause of all causes who is God. So he sees the writer as the agent of writing. This is extreme foolishness. Those who are experienced in spiritual things and whose inner light has been enkindled understand that God gave every atom of the heavens and earth power of speech with which they speak (evidence $=$ burhan) and they have got such tongue by which they speak without voice (abstraction). Those who are unable to hear it do not hear it (cannot explain the Signs of Allah, the ayat by abstraction).

On the same topic wrote Ibn Al-Arabi (trans. Chittick, 1989, op. cit.): "Two ways lead to the knowledge of God... The first way is the way of unveiling... The second way is the way of reflection and reasoning (istidlal) through rational demonstration (burhan aqli). This way is lower than the first way, since he who bases his consideration upon proof can be visited by obfuscations which detract from his proof, and only with difficulty can he remove them" [slightly edited by author].

The fact that the scholastic Islamic scholars practiced the logical understanding of the Tawhidi worldview is attested by Bakar (1991, p. 6): "Logical thinking, mathematical analysis, observation, experimentation, and even rational interpretation of sacred Books all have their legitimate roles to play in the scientific enterprise of early Muslim scientists."

Yet it is true that the above kind of Tawhidi methodological formalism has not been translated into science and society relations, and thereby in economics and finance (muamalat). The Tawhidi String Relation as the process-based methodology of learning in unified worldsystems comprises the logical formalism of the Tawhidi worldview at a time when the age of metaphysical scholarship has been succeeded by the rise of mind and matter pursuit. 
to project this essence into the financial engineering model of behavior and measurement in the Islamic case of asset-valuation.

We refer back to expression (1) and Fig. 2 (vis-à-vis Fig. 1) to structure the following steps in the Islamic financial engineering model of asset-valuation. Note first what we mean by risk and return relationship in reference to expression (1) and how it projects itself in Fig. 1.

\section{Risk and Return in Response to Islamic Epistemology of Unity of Knowledge or Pervasive Complementarities of the Tawhidi world-systems ${ }^{(6)}$}

Since every process in the TSR learns to a point but never reaches such a point perfectly due to evolutionary dynamics, therefore, there is a consensual

(6) The topic of pervasive complementarities and the risk-return analysis vis-à-vis the methodology of Tawhidi unity of knowledge and the world-system is further explained now to remove the misconception surrounding them.

These precepts are derived from the Qur'anic interpretation of the paired universe of 'everything' (Qur'an, 36:36) and the Qur'anic learning universe (Qur'an, 29:19-20) of unity of life and being.

Firstly, one notes that scarcity of resources and competition expressed by marginal rate of substitution is the underlying and interconnected results on resource allocation in mainstream economics. But if you view the resource allocation problem in the light of a continuously learning and unified entity-relationship every given resource allocation between entities leads into organic evolution to more opportunities thus there is simply an instantaneous moment where a mathematical truism of allocation of a given resource is made at a point on the production possibility curve and thereby on the consumer and investor indifference curve. In the continuous sense, the instantaneous allocation point is replaced by the evolution of learning, and thereby, of fresh generation of resources. This causes the allocation point to evolve, and preordering of preferences and choices are replaced by a multitude of probabilistic possibilities in a field surrounding the allocation point. This case is generalized.

The fact is that no where it is implied that all of the possibilities gain the same denominations of increased shares. Yet they both increase from the previous levels. In other words, if $\mathbf{x}$ is a vector of possibilities, then $\mathrm{d} \mathbf{x} / \mathrm{d} \theta>0$ implying that $\mathrm{dx}_{\mathrm{i}} / \mathrm{dx}_{\mathrm{j}}>0$, for each $\mathrm{i}, \mathrm{j}$-indexed variables of $\mathbf{x}$. Also then, $d^{2} \mathbf{x} / d \theta^{2}>0$, and $(d / d x j)(d x i / d x j) \neq 0$, since every element of $\mathbf{x}$ is continuously $\theta$-induced positively.

As shown in Fig. 3, the presence of $\theta$-induction of the variables shown makes these evolve along the risk-diversification axis even as expected return increases but leaving no optimality in the expected utility function or at any point of allocation of the risk-return measures. Contrarily, in the mainstream economics that is entrenched on the optimality consequences caused by resource scarcity, competition and preordering assumptions,. there is no learning at such optimal points. Novelty of organic learning has disappeared.

Next let us answer the question of discounted intertemporal expected utility function just as we do in the case of a discounted intertemporal consumer utility function. Risk-return behavior of mainstream economics is now carried over time in which discounting is made to signify the marginal efficiency of investment. See Jean (1970). In the Islamic case, such an indicator cannot exist, as probabilistic fields environ the intertemporal return and riskdiversification points continuously by learning. 
knowledge-flow ' $\theta$ ' arising out of shuratic discourse. The meaning of the shura is used in the extensive meaning of organic participation. The shuratic learning is extended to system-consciousness (tasbih) when dealing with the worldsystem (Qur'an, 49-53). The true value of $\theta$ denoted by $\theta^{*}$ is never known, nor is it necessary to know it $(g h a y b)$. The learning nature of TSR simply approximates to this unknown value through a gradual actualization of unity of knowledge in the world-system as derived from $(\Omega, S)$.

The variance of prospects is now denoted by the following expression: Let $\left(\theta_{\mathrm{i}}, \mathbf{x}_{\mathrm{i}}\left(\theta_{\mathrm{i}}\right)\right)=\mathrm{Z}_{\mathrm{i}}$. Then, $\operatorname{Var}\left(\mathrm{Z}_{\mathrm{i}}\right)=\Sigma_{\mathrm{i}} \mathrm{p}\left(\mathrm{Z}_{\mathrm{i}}\right) \cdot\left(\mathrm{Z}_{\mathrm{i}^{-}} \mathrm{Z}_{\mathrm{i}}^{*}\right)^{2}$, for every interactively integrated region of socioeconomic and institutional complementarities. $\left(Z_{i}\right.$, $\left.\mathrm{Z}_{\mathrm{i}}{ }^{*}\right) \in \cup_{\mathrm{i}} \cap_{\mathrm{j}}\left\{\mathrm{Z}_{\mathrm{ij}}\right\}$, for each $\theta_{\mathrm{ij}} \in(\Omega, \mathrm{S})$ for $\mathrm{i}$-numbered interaction, $\mathrm{j}$-numbered integration, and subject to the condition of evolutionary dynamics (Choudhury, Zaman \& Al-Nasr, 2007), $\mathrm{d} \cup_{\mathrm{i}} \cap_{\mathrm{j}}\left\{\theta_{\mathrm{ij}}\right\} / \mathrm{d} \theta_{\mathrm{i}}>0$; with $\theta_{\mathrm{i}}=\operatorname{plim}\left\{\theta_{\mathrm{ij}}\right\}, \mathrm{i}, \mathrm{j}$ defined as above. Consequently, by virtue of the monotonic continuous relationship, $\mathrm{d} \cup_{\mathrm{i}} \cap_{\mathrm{j}}\left\{\mathrm{Z}_{\mathrm{ij}}\left(\theta_{\mathrm{ij}}\right\} / \mathrm{d} \theta_{\mathrm{ij}}>0\right.$, with $\mathrm{Z}_{\mathrm{i}}=\operatorname{plim}\left\{\mathrm{Z}_{\mathrm{ij}}\right\}$. Such probability limits are explained by Chaos Probabilities over complex fields of interaction, integration and coevolution of similar patterns (Kellert, 1993). Note also what Keynes had to say about the complexity of such subjective probabilities (O'Donnell, 1989). Since, integrations emanate from interactions, therefore $\left(Z_{i}, Z_{i}^{*}\right)$ are pervasively subject to the IIE-characteristics of learning in TSR, as explained earlier ${ }^{(7)}$.

(7) Next to align the above explanation on the intertemporal validity of discounted expected utility function, though Fig. 3 gives only the present-time analysis, we note the completely opposite explanation of the Islamic investment approach to risk-return in a complex learning domain of simulation. This totally rejects the neoclassical, and thus the standard approach to risk-return optimization problem in the mainstream literature. The underlying force is that of risk-diversification, as product diversification increases, and thus expected return increases or stabilizes in a learning field with increasing risk-diversification. Thereby risk-propensity does not decrease the expected utility function of the investor. Thus, only the present moment near to an asset valuation point is sacrosanct not the discounted future in terms of an intertemporal expected utility function in risk and return and its derived result in terms of investor indifference curve.

The above fact is explained further by formalism in probabilistic learning fields of resource allocation. Here is a brief formalism in this case.

The probabilistic model of learning fields in respect of the risk and return analysis of complementary processes is specified by the asset valuation model. In such a case choices are not governed by the assumptions of rational choice behavior of mainstream finance. That is because the resource scarcity axiom of mainstream economics and finance is abandoned. It is replaced by a continuous reproduction of resources through the medium of continuous learning. The implication is this. With an increase in learning by participation between money, real economy, markets, and agents (investors) a consensus is arrived at as to the nature of economic evolution after considering various different contingencies of the state of nature. Asset evaluation is then done at the proximity of a forward looking perspective of the 
Next the principle of pervasive complementarities implies that $d \operatorname{Var}\left(\theta_{\mathrm{i}}\right) / d \theta_{\mathrm{I}}$ $<0$. This is the consequence of effective risk-diversification both in the systematic and non-systematic cases. The necessity for risk-diversification follows from one of the five goals of the Shariah, namely protection of property rights. But risk-diversification necessarily requires its complementary productdiversification (Choudhury \& Hoque, 2004).

Furthermore, over continuums of learning processes as in expression (1), attained levels of complementary product and risk diversifications reinforce each other. This is the result of the principle of pervasive complementarities. It is based on circular causation relations that simulate the social wellbeing criterion.

Therefore, $\mathrm{d} \operatorname{Var}\left(\mathrm{Z}_{\mathrm{i}}\right) / \mathrm{d} \theta_{\mathrm{i}}<0 \Leftrightarrow \mathrm{dE}\left(\mathrm{Z}_{\mathrm{i}}\right) / \mathrm{d} \theta_{\mathrm{i}}>0$. Consequently, $\mathrm{dE}\left(\mathrm{Z}_{\mathrm{i}}\right) / \mathrm{d} \operatorname{Var}\left(Z_{\mathrm{i}}\right)<0$. That is, as risk-diversification or product-diversification

states of nature and knowledge building. This is referred to as the forward looking overlapping generation model of asset valuation.

Accordingly, evolutionary trends in $\theta$ is causally interrelated as follows:

$\theta \uparrow \Leftrightarrow\left[\theta \rightarrow \theta^{*}\right],\left[\mathrm{x}(\theta) \rightarrow \mathrm{x}^{*}\left(\theta^{*}\right)\right]$

$\Leftrightarrow \mathrm{E}[\mathrm{f}(\theta, \mathbf{x}(\theta))]=\mathrm{f}\left(\theta^{*}, \mathbf{x}^{*}\left(\theta^{*}\right)\right)+$ higher positive terms.

i.e. $\mathrm{E}[\mathrm{f}(\theta, \mathbf{x}(\theta))] \uparrow$

Besides, $\theta \uparrow \Leftrightarrow \operatorname{Var}[\mathrm{f}(\theta, \mathbf{x}(\theta))] \downarrow$ but non-vanishing.

Therefore,

$\{\mathrm{dE}[\mathrm{f}(\theta, \mathbf{x}(\theta))] / \mathrm{d} \theta\} /\{\mathrm{d} \operatorname{Var}[\mathrm{f}(\theta, \mathbf{x}(\theta))] / \mathrm{d} \theta\}<0$

This result is contrary to the one obtained on risk-return analysis by optimization of the expected utility function. The contrary result in our case is caused by the appearance of $\theta$ value in the expected utility function, which renders the utility function to be un-optimizable. Only simulation over $\theta$-values and the consequent $\mathrm{E}[\mathbf{x}(\theta)], \operatorname{Var}[\mathbf{x}(\theta)]$ is possible under the condition of declining risk with increasing expected value caused by risk and product diversifications conterminously.

Lastly, we reflect back on the probabilistic field surrounding the emergence of $(\theta, \mathrm{E}(\mathbf{x}(\theta), \operatorname{Var}(\mathbf{x}(\theta)))$ in the overlapping generation model of asset valuation. Mathematically, the intricacies of the conditional probabilities signify the interactive, integrative and evolutionary learning process between market realities, ethical learning by institutional guidance, preference change and unity of knowledge. But in the practical sense of asset valuation for the practitioner, the probability measures are assigned by discourse in the proximity of dated flows of $\mathbf{z}=(\theta, \mathrm{E}(\mathbf{x}(\theta), \operatorname{Var}(\mathbf{x}(\theta)))$ in asset valuation along the forward movement of the overlapping generation model. Such probabilities never attain the value 1 . But they are monotonically related to $\theta$-values in the probability limiting sense. Consequently, higher asset valuation is obtained under the following condition:

$\theta \rightarrow$ monotonically discursively assigned probability values

$\rightarrow$ monotonically $\{\mathbf{z}=(\theta, \mathrm{E}(\mathbf{x}(\theta), \operatorname{Var}(\mathbf{x}(\theta)))\}$

$\rightarrow$ monotonically asset valuation in the overlapping generation model

$\rightarrow$ monotonically social wellbeing function connected with the overlapping generation model 
take effect, a decreasing risk factor increases product-diversification; an increasing product-diversification enhances risk-diversification.

The result so obtained in the light of TSR is contrary to the risk-return postulates and preference behavior of mainstream financial engineering theory. In mainstream theory a future gamble incites behavior to higher expectation as risk increases. This is called risk-aversion. It emanates from the nature of risk and return in the expected utility function. In mainstream financial engineering this result is interpreted as a gamble of higher risk for attaining higher expected return. From this kind of preference behavior emanate the speculative, hedging and option instruments of futures. Then upon them, debt-instruments like bonds follow suit. Government bonds are included in this, for Government bonds do not cultivate the economic conditions for effective product-diversification when governments tend to be risk-neutral, and thereby, the government asset portfolio is not risk-diversified.

Figure 2 is now interpreted like this: Preferences for complementarities between product-diversification and risk-diversification lead to an increase in venture capital in projects that create social wellbeing as defined earlier. Consequently, organic linkages appear between the socioeconomic, financial and monetary sectors. Institutional policy instruments, such as those promoted by venture capital centering on cooperative development financing instruments, mudarabah, musharakah, shareholding, and Foreign Trade Financing, gain grounds. Such instruments are the result of contracts and are therefore learned out of a combination of rule formation (ahkam al-mu amalat), shuratic discourse, preference dynamics, organic understanding of socioeconomic realities, and institutional agency. All together these activities simulate the social wellbeing criterion with circular causation between the emergent complementary variables including evolutionary knowledge-flows.

Consequently, no optimal point of resource allocation, and thereby, no steady-state equilibrium point can be determined, as otherwise is the case in mainstream financial economic and finance theories. Figure 1 and 2 have similar implication on recursive feedback between cause and effect. Yet they have opposite implications in terms of complementarities between the good things of life in the TSR and substitutions within complementarities between the rivals of competition and scarcity in mainstream theory.

Figure 3 brings out the above points. In mainstream financial engineering, point ' $A$ ' being the optimal uncertain point it depends upon a risk-aversion behavior with the vertical axis being for Risk of sth-prospect $X_{s}\left(\operatorname{Var}\left(X_{s}\right)\right)$ and the horizontal axis for expected returns $\mathrm{E}\left(\mathrm{X}_{\mathrm{s}}\right)$. In the region of ' $\mathrm{A}$ ', riskdiversification weakens. Consequently, product-diversification also weakens 
with decreasing increments in expected returns as risk increases away from the budget line TT.

But the axes for the Islamic case are $\left(\mathrm{DV} \operatorname{ar}\left(\mathrm{Z}_{\mathrm{i}}\right)\right.$ : risk-diversification) in the vertical axis; $E\left(Z_{i}\right)$ in the horizontal axis. Now learning behavior in the TSR with circular causation between financial and real economic variables (socioeconomics) causes the same point ' $\mathrm{B}$ ' to become simulative fuzzy (complexity) region. Consequently, the complementarities between productdiversification and risk-diversification result in rightwards shifting positively sloped risk-return allocation curve subject to learning resource line T' $T$ '. The latter is due to the fact that learning is like technological induction. It creates new opportunities, hence evolutionary learning.

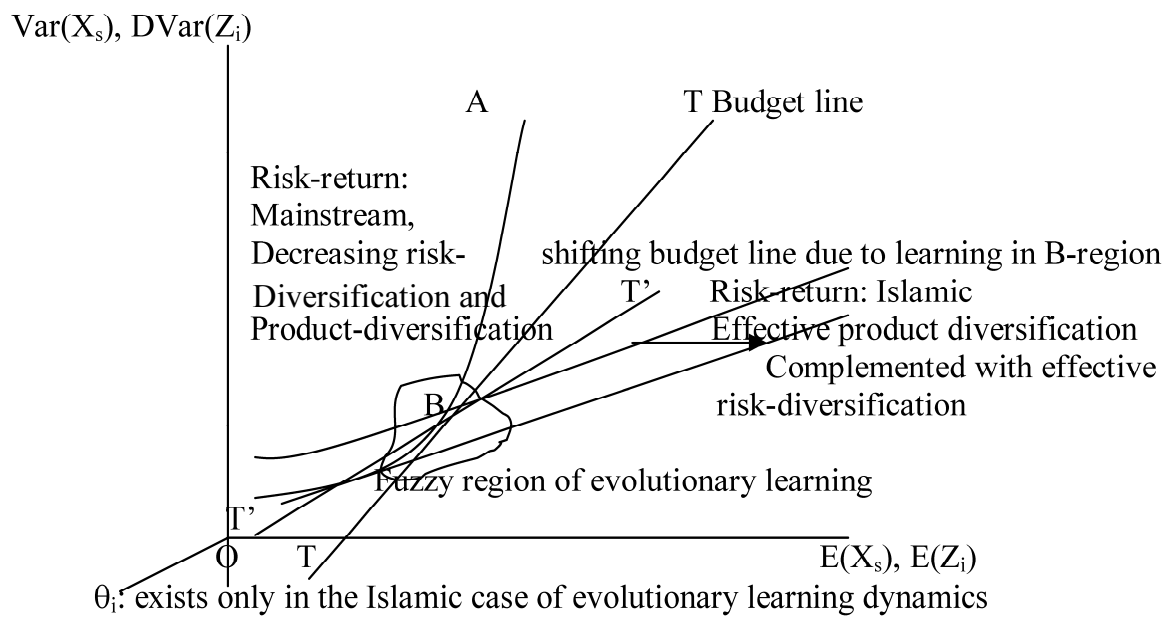

Fig. 3. Resource Allocation and Risk-return Behavior in Islamic Versus Mainstream Financial Engineering Cases.

One may ask: How do the Islamic investor, individual, and institution including government respond to risk per se? The organization of learning as the part and parcel of the Islamic money, finance and real sector circular causation relationship in the form of linkages between these, formulates the aversion to risk. We understand though that risk will always be there in any venture and decision, and the investor would then need due protection against risk. Protection is gained from diversifying risk and production as a complementary whole. In such a relationship, the individual and investor learn regarding preferences and development menus along the lines of dynamic lifefulfillment regimes. Governments must never bear total risk by themselves. Rather, as an institution, any government level ought to cooperate with the private sector to participate in the systematic functions of risk and product 
diversifications. The attitude to risk though of the risk-aversion type is not explained by a utilitarian behavior under conditions of financial instruments that intervene in the financial market while allowing risky assets to enter freely ${ }^{(8)}$.

Hirshleifer (1965) points out that the risk-return analysis of mainstream economics and finance does not study the coterminous economic and financial problems together. This is the same thing as was pointed out earlier in this paper. The money and finance on one side and the real economy on the other side pursue competing ends. Resource allocation in such a case is thus explained by the postulate of marginal substitution as opposed to the principle of pervasive complementarities in the Islamic resource allocation case. An Islamic system that increasingly moves into risky assets becomes speculative and untenable. Short-term interest rates in all likelihood enter the mechanism of relative arbitrage pricing between the financial and real economic sectors. Along with this, all the methods of mainstream financial engineering will also confound Islamic financial accounting ${ }^{(9)}$.

(8) Here is evidence on the non-optimal nature of risk and return relation in the Islamic case qua rational behavior of mainstream theorizing.

The number of rich households and their wealth in the GCC region (CAGR for liquidity was $7 \%$ between 2003 and 2007; number of wealthy households increased by 6 per cent CAGR between 2003 and 2007) increased even as GDP and privatization picked up (CAGR of nominal GDP was 19 per cent between 2002 and 2006). Within the wealth formation there was a 40 per cent share of the capital market that preferred Islamic over conventional funds. There was preference for high returns over stable return among this class of investors. Additionally, 20 per cent of the market share in the GCC region was made up of investors that preferred pure Islamic funds. These investors preferred Shari'ah-compliant investments over conventional ones, no matter what was the performance of Islamic funds. The rest of the 40 per cent share of the capital market was of investors in the GCC region preferring conventional funds.

(9) Composition of the Islamic capital market was made up of portfolios of equity (sukuk, CAGR 232 percent between 2002 and 2006; private equities CAGR 36 per cent between 2000 and 2006), real estate (CAGR 36 per cent between 2002 and 2006), and Islamic insurance (Takaful, CAGR 13 per cent between 2002 and 2005). In general, Islamic funds increased by CAGR 22 per cent between 2000 and 2006, but with a focus on medium to small enterprises.

The Islamic investment picture for the MENA region is similar. Forty per cent of MENA Islamic investments were in real estate. This is followed by 17 per cent in financial services; 14 per cent in travel and tourism; and 29 per cent in private equities. In all, Islamic funds in MENA experienced a CAGR of 130 per cent between 2002 and 2006.

These trends bring to light the fact that moderate but stable (approximately 7 per cent in Islamic bank share deposits) expected returns satisfy Islamic investors. This preference over conventional investment funds (60 per cent of all investors in the GCC region) intensifies with increasing Islamic orientation (the $\theta$-value). Such investors face risk levels that are lower than the conventional ones. This fact is actuated by a phenomenal increase in sukuk (Islamic bond) funds representing Islamic equities and real estate that by their very nature are low risk with good return for rich investors. On the other hand, conventional investment funds in the GCC area experienced a sharp market correction, declining in returns by 38 per cent between 


\section{Part 3 \\ Formulating the Asset-Valuation Model in the Islamic Case}

We have now established that three elements are fundamental in realizing valuation in any case - money, finance and real sectors. These are led firstly by the complementary operation of preferences driving the precept of unity of knowledge into the world-system. Secondly, the participatory socioeconomic system including money, finance and real economy are organized along lines of the Tawhidi pairing principle of unity of knowledge. Thirdly, there is the institutional role through discourse to evolve rules of management of the socioeconomic order. This is the embryonic nature of the shuratic process in the extensively participatory world-system. The compounding of these PrincipalAgent activities in the Islamic case looks after the wellbeing criterion along with its analytical details, as defined earlier. Systemic learning emerges and perpetuates in continuum according to the IIE-characteristics of processes $\left(\mathrm{P}_{\mathrm{i}}\right)$ as indicated in expression (1).

Now every process point $P_{i}$ along the forward moving time-trends in asset values can be seen as an event reflecting interaction, linkages (integration) and co-evolution by simulated processes of learning post-evaluation of social wellbeing. The net result of the compound learning elements as indicated in Fig. 2 generates interrelationships across further evolutions through the simulation of $\left\{\theta_{t}\right\}$-knowledge-flows. The degree of determinism of the 'nearest' processvalues $\left(Z_{i}\left(\theta_{i}\right)\right)$ remain only probabilistically 'near' to evaluation points $\left(Z *\left(\theta_{i}\right)\right)$ along the life-cycle of the asset. Each such valuation point is thus the result of the IIE-characteristics as explained. The onward moving asset-valuation under the impact of the IIE-learning processes of IIE-characteristics occurring in concert with the socioeconomic variables and shuratic discourse establishes the overlapping generation valuation model. This is explained below as the financial engineering model of Islamic asset-valuation in contrast to and rejection of the mainstream financial engineering ones.

\section{Overlapping Generation Model of Asset-valuation in the Islamic Case}

The overlapping generation model for the Islamic case is now formalized. Let the knowledge-induced cash-flows be denoted by $\left\{\mathrm{A}_{\mathrm{t}}\left(\theta_{\mathrm{t}}, \mathbf{x}_{\mathrm{t}}\left(\theta_{\mathrm{t}}\right)\right)\right\}$ over time ( $\left.\mathrm{t}\right)$ as shown in Fig. 4.

2005 and 2006. This decline is followed by very weak recovery in 2007. Our implications of money-finance-real economy circular causation relations are reflected in the choice of Islamic diversified portfolio contrary to the independence of the financial sector as a competing one with the real sector.

Thus our risk-return results in the Islamic case are supported by the real evidence of the GCC area. The same is found true of MENA Islamic investments and South-East Asia (Bangladesh, Malaysia, Indonesia). 


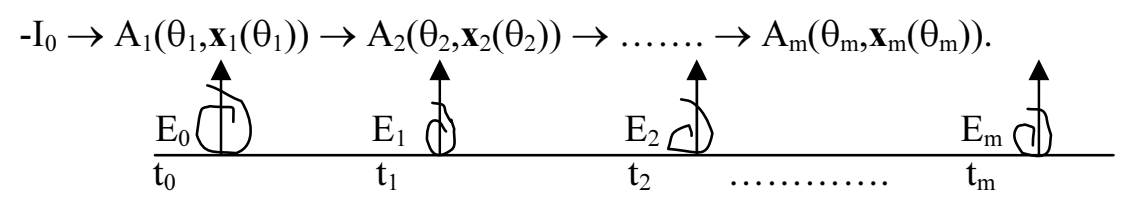

Overlapping generation asset-valuation points

Fig. 4. Recursively Generated Knowledge-Induced Cash-Flows in the Overlapping Generation Valuation Model.

At time periods $t_{0}, t_{1}, t_{2}, \ldots, t_{m}$ there are corresponding recursive interrelations between the $(\theta, \mathbf{x}(\theta))$-variables in the sense of knowledge-induced simulations of the wellbeing criterion. This method is explained below.

The circular causation recursive relations explained in Fig. 2 are shown by at $E_{0}, E_{1}, E_{2}, \ldots, E_{m}$ by $\circlearrowright$ Clearly now, an infinite-term compounding is not applicable, because only finite-term decision-making is possible in the shuratic process, while evolutionary processes continue.

The recursive relations implicative of complementarities between the $\mathbf{x}(\theta)$ variables are expressed as follows:

$$
\mathbf{x}_{\mathrm{t}}{ }^{\prime}\left(\theta_{\mathrm{t}}\right)=\mathrm{f}\left(\theta_{\mathrm{t}-1}, \mathbf{x}_{\mathrm{t}}\left(\theta_{\mathrm{t}-1}\right)\right) .
$$

Here $\mathbf{x}_{\mathrm{t}}\left(\theta_{\mathrm{t}}\right)$ denotes the vector of variables except the one that becomes the dependent variable, $\mathbf{x}_{\mathrm{t}}{ }^{\prime}\left(\theta_{\mathrm{t}}\right)$, at every point of time in the simulation system of recursive interrelations.

Furthermore, for the simulated value of $\theta$-values we note:

$$
\begin{aligned}
& \theta_{\mathrm{t}}^{\prime}=\mathrm{g}\left(\theta_{\mathrm{t}-1}, \mathbf{x}_{\mathrm{t}}\left(\theta_{\mathrm{t}}\right)\right), \\
& \theta_{\mathrm{t}}=\operatorname{plim}_{\mathrm{j}=1 \rightarrow \mathrm{m}}\left\{\theta_{\mathrm{tj}}\right\},
\end{aligned}
$$

The above expressions are true for interaction 'nearest' to every point of time t. $\mathrm{j}=1,2, \ldots, \mathrm{m}$ are integrations resulting from the interaction within each time period, for $\mathrm{t}=1,2, . ., \mathrm{n}$.

\section{Further Development of the Overlapping Generation Model: Debt/Equity Swapping}

Take the example of debt-equity swap in the overlapping generation model. In this case, let $\mathbf{x}_{\mathrm{t}}\left(\theta_{\mathrm{t}}\right)=\{\mathrm{D} / \mathrm{K}, \mathrm{g}(\mathrm{K}) / \mathrm{g}(\mathrm{D})\}\left[\theta_{\mathrm{t}}\right]$, where $\mathrm{D}$ denotes value of debt, $\mathrm{K}$ denotes capital formation generated by equity participation. $g(K)$ and $g(D)$ denote growth rates linked with equity and debt, respectively. Let $\theta_{\mathrm{t}}$-values be consensually derived knowledge values over time and centered on directing foreign investment into debt-equity swaps through the instruments of 


\section{mudarabah, musharakah, joint ventures, re-takaful (re-insurance) ${ }^{(10)}$. Such}

(10) The analysis of economic cooperation in the broadest sense of entity-interaction that Muamalat studies is a derivative of the Tawhidi relational worldview (TSR) by virtue of the development financing instruments and the shari'ah-compliant outlets that are invoked in the spending portfolio. Among these the principal ones practiced in the conventional Islamic finance literature are mudarabah, musharakah and murabahah. Secondary financing instruments are deeply questionable ones in terms of their Shari'ah legitimacy, although such instruments are being used (Rosly, 2005).

The different and more focused implications of complementarities between the financing instruments are to combine the principal financing instruments into a new one. Here is an example.

The principal Islamic project financing instruments are known to be profit-sharing (mudarabah) and equity-participation (musharakah). But nowhere in the conventional literature in Islamic economics and finance are these instruments treated in the economy-wide and society-wide context of learning linkages - generating systemic synergy. Hence, the fundamental essence of cooperation and participation across sectors, economy-wide and society-wide, has not been treated in the literature and practice. Consequently, the abovementioned MM-instruments turn out to be focused merely on the profitability goal of a project. Short-run financing is emphasized. Long-term financing and medium-term financing are treated residually in Islamic finance.

Consequently, the socio-economic development issues that rest on the maqasid as-Shari'ah are by and large ignored on the pretext of 'priority', and only one of all the Shari'ah injunctions, namely, maintenance of shareholders' property rights is pursued. This translates into maximization of shareholders' wealth, and thus maximization of the value of the financial firm. Islamic financing institutions have remained ambivalent to the social application of project-financing by sectoral linkages and institutional networking. As an example, no MM-project is found that has a component goal of poverty alleviation in it that is complemented by profitability goal. Consequently, the comprehensive objectivity of the Shari'ah (maqasid al-Shari'ah) has been sacrificed in this one-dimensional economic and financing focus. Jabsheh et al., (2007) is a clear example showing how Islamic financing practice has missed out the maqasid al-Shari'ah.

Cost-plus pricing method (murabahah) is another instrument that is extensively practiced in trade-financing and asset sales. Yet, to be Shari'ah-compliant, Murabaha must revolve around mudarabah and musharakah taken up conjointly in reference to market valuation of assets. Such complementary development-financing instruments (MMM) would then possess the essential character of economy-wide and society-wide diversity and linkages by the synergy of inter-relationships according to the comprehensive objectives of the maqasid alShari'ah.

Because the above-mentioned MMM-financing instruments in theory and practice are devoid of the essential need for economy-wide participatory extensions, therefore, any secondary financing instrument revolving around the prevalent MMM-financing, seen as sleeping partnerships, cannot qualify for the truly Islamic instrument of development-financing. Examples here are unit trust (amanah sahm) and sukuk (mudarabah bonds). Likewise, even shareholding in Islamic bank PLS accounts and similar instruments need to be refined by accommodating the extensive meaning of the Maqasid as-Shari'ah (Mydin \& Larbani, 2006).

The substantive issues here are more than simply an instrument being asset-backed as opposed to liquidity-backed. Mere asset-backed financing can fail to meet the maqasid alShari'ah, if the social and economic sustainability are not engineered on the basis of the 
resource mobilization into the real economy performing the much-needed production and risk diversifications bring about linkages between these two, as long as the development financing instruments are treated in the cooperative sense of extensive organic participation ${ }^{(1)}$. Consequently, interest-based

Tawhidi implication of learning intra- and inter- systems through complementarities ('pairing'). Thus the argument made by some in support of sukuk (Kahf, 2007) remains untenable in the absence of such embedded linkages vis-à-vis the maqasid al-Shari'ah. Along with this grand remiss both in Islamic economic and finance scholarship and in practice, sustainability of these fields for the uplift of the Ummah the conscious world-nation of Islam, remains in serious question. The absence of Tawhidi worldview of unified linkages drives the Muslim mind and institutions into this kind of isolationism and absence the Islamic worldview.

Asset-backing in both the economy-wide and society-wide sense with a mix of short-term, medium-term and long-term complementary goals can be attained by linking up the monetary sector with the real sector through the medium of new financing instruments. Unless the resulting circular causation as endogenous learning relationships are not attained between money, real economy and financing instruments in the comprehensive sense of Maqasid as-Shari'ah, the goal of the Islamic economy to attain wellbeing (falah and tazkiyah) through the medium of a riba-free economy and a just society, cannot be achieved. In the absence of such economy-wide and society-wide participatory transformation, neither an Islamic change is possible nor can the large liquidity of Islamic banks be mobilized into truly Shari'ah-compliant outlets to attain the maqasid al-Shari'ah.

Besides, the extension in such a transformation process invokes the important possibility for the coterminous attainment of production-diversification and risk-diversification. These conditions are essential to attain cost-effective sustainable growth, and development and creative evolution of economy and society. A joint production function is now made the engine of resource mobilization in the complementary domain of total economicdiversification. The financing instruments in the money-real economy linkage must be based on and be capable of mobilizing resources to achieve this extensive inter-sectoral picture (Choudhury \& Hoque, 2004). Such extensively paired meaning of socioeconomic structure can be derived from verse (2:164). It is guidance premised on the organic unity of the divine law working throughout all world-systems.

Finally, our financing instrument is a combination of MMM-instruments that satisfies the maqasid al-Shari'ah by mobilizing all forms of resources economy-wide and society-wide to attain Social Wellbeing. At a pragmatic level, such a financing instrument is a pure shareholding. It swims across hybrid capital stocks in diverse sectors. Funds can freely diversify between MMM-instruments according to the SWI-criterion. Thus, while a legal ledger will be maintained for the respective $\mathrm{M}, \mathrm{M}, \mathrm{M}$ for the benefit of the shareholders and financier, yet the economic and social meaning is an integrated one. Invested funds can flow freely between the MMM (Choudhury, 2000).

A close management of such a fund necessitates cooperation between the banking and nonbanking institutions. Therefore, complementarities must be progressively extensive between the sectors and between institutional and policy simulations economy-wide and society-wide. Islamization in its true sense of synergetic learning in unity of knowledge referring to ayatAllah becomes the goal of the Ummah. The Qut'anic verse (2:164) implicates such blessings that ensue from the evidences of ayat-Allah.

(11) A cursory quantitative example of estimating the intergenerational asset valuation model is given in the paper. But the author's elaborate empirical work on a research work has been 
financing becomes redundant in such a complementary system. Thus the Islamic regimes are defined by regimes of $\left(\theta_{t}, \mathbf{x}_{\mathrm{t}}\left(\theta_{\mathrm{t}}\right)\right.$-values over time in the TSR now applied to Islamic financial engineering.

Every flow of foreign equity capital like $\mathrm{I}_{0}$ used in debt-equity swap yields a terminal value of cash-flows or asset-valuation at time t. This is denoted by $\mathrm{A}_{\mathrm{t}}\left(\theta_{\mathrm{t}}, \mathbf{x}_{\mathrm{t}}\left(\theta_{\mathrm{t}}\right)\right)$. $\mathrm{A}_{\mathrm{t}}\left(\theta_{\mathrm{t}}, \mathbf{x}_{\mathrm{t}}\left(\theta_{\mathrm{t}}\right)\right)$ then accumulates by the profit-sharing rate until maturity of the debt-equity swap. $A_{t}\left(\theta_{t}, \mathbf{x}_{t}\left(\theta_{t}\right)\right)$ thus enters as a variable in the wellbeing function, performing the circular causation complementary relationships with other variables.

We now have the overlapping generation valuation model based on the simulated $\left(\theta_{\mathrm{t}}, \mathbf{x}_{\mathrm{t}}\left(\theta_{\mathrm{t}}\right)\right)$-values. An appropriate selection of the policy variables (control variable along with the $\mathbf{x}_{\mathrm{t}}$-vector is $\delta=\{(\mathrm{K} / \mathrm{D})$-ratio, $(\mathrm{g}(\mathrm{K}) / \mathrm{g}(\mathrm{D}))$ ratio $\}$. These two ratios are moved toward equality with each other by means of a institutionally discursive control of the $\delta$-parameter in the presence of limiting $\theta_{\mathrm{t}}$-values (weights).

The complete simulation of the overlapping generation valuation model is now given by, ${ }^{(11)}$

presently funded by a grant from the Postgraduate Studies and Research Department in Sultan Qaboos University. The project is expected to complete in 2009.

It is noted that the overlapping generation asset-valuation model under study is quite distinct from the neoclassical overlapping generation model because of the learning, institutional and endogenous ethical induction at every point of forward decision-making and choices, where rationality assumptions do not apply. Only unity of knowledge by a continuous process of correction and regeneration and point-wise evaluation of returns by probability measures of the quantum-genre are used. Discounting of cash-flows is rejected.

In the neoclassical form of the overlapping generation model, discounted future cash- flows under different contingencies are used. For example, in the case of Hirshleifer (1970) the discounted cash-flows $\left(\mathrm{C}_{\mathrm{a} 1}\right)$ for the present generation (1) that overlaps with its contiguous future generation (2) with cash-flow $\left(\mathrm{C}_{\mathrm{b} 2}\right)$ with different contingencies $(\mathrm{a}, \mathrm{b})$, such as agedistributions of young and old populations, respectively, is given by the present-value of contingent future cash-flows, $E(C)=C_{a 1} /\left(1+d_{a 1}\right)+C_{b 2} /\left(1+d_{b 2}\right)$, with $d_{a 1}$ being the discount rate of one-period cash-flows of the young population; $d_{b 2}$ being the discount rate of oneperiod cash-flows of the old population. Furthermore, if we write, $E(C)=\phi(C) /(1+d)$ to express the overlapping generational cash-flow than ' $d$ ' is a subjective function $(\mathrm{f})$ of cashflows and contingent-based discount rates. Let this be

$\mathrm{d}=\mathrm{f}\left(\mathrm{C}_{\mathrm{a} 1}, \mathrm{C}_{\mathrm{b} 2}, \mathrm{~d}_{\mathrm{a} 1}, \mathrm{~d}_{\mathrm{b} 2}\right)$. However, in the case of the Islamic overlapping generation model in this paper the discounting method is not applicable. Besides, even in Hirshleifer's time contingency model under uncertainty, the discount ' $d$ ' rate is subjective in nature.

Rasmussen and Rutherford (2001) overlapping generation model is an intertemporal household utility function of consumption flows expressed as a discounted sum of intergenerational cash-flows with different generation groupings that are endowed by their respective consumption bundles. The discount rate is subjective and untenable for our OGM. 
Simulate $_{\{\theta t\}} \mathrm{W}(\theta)=\sum_{\mathrm{t}=1}{ }^{\mathrm{n}}\left[\mathrm{A}_{\mathrm{t}}\left(\theta_{\mathrm{t}}, \mathbf{x}_{\mathrm{t}}\left(\theta_{\mathrm{t}}\right)\right)\right]-\mathrm{I}_{0}$,

with $\theta$ denoting the sequence of consensual $\theta_{\mathrm{t}}$-values over time,

subject to the knowledge-flows and time-dependent recursive interrelations shown in (2)-(4).

We now have the following kind of simulative knowledge-induction: As foreign investments $(\mathrm{I}(\theta))$ are directed into musharakah projects through retakaful, $(\mathrm{D} / \mathrm{K})$ tends adaptively towards $(\mathrm{g}(\mathrm{K}) / \mathrm{g}(\mathrm{D}))$, as $\delta$ assumes a value near to unity when all of debt is swapped by a proportion of the foreign investment flow in joint venture. Ultimately, no interest remains hanging, for debt is retired. Simulative $\theta_{\mathrm{t}}$-values appear from the discursive decision-making and polity-market processes by virtue of using ways and means of effectively mobilizing such foreign investments into cooperative projects. Complementary relations between debt reduction and equity swap are sustained. Interest-based regime is progressively replaced by profit-sharing rates along the learning path of asset-valuation.

In the specific case of debt-equity swap the wellbeing objective criterion means the sum-total of all debt write-offs by the progressive upward movement of the $\delta$-ratios.

For the particular case where cash-flows are generated by compound values of profit-sharing rates $\left(r_{t}\right)$ at every time-period, we take $x_{t}\left(\theta_{t}\right)=r_{t}\left(\theta_{t}\right)$.

$$
\mathrm{W}(\theta)=\sum_{\mathrm{t}=1}{ }^{\mathrm{n}} \mathrm{A}_{\mathrm{t}}\left(\theta_{\mathrm{t}}, \mathbf{x}_{\mathrm{t}}\left(\theta_{\mathrm{t}}\right)\right)=\sum_{\mathrm{t}=1}{ }^{\mathrm{n}}\left[\mathrm{A}_{\mathrm{t}}\left(\theta_{\mathrm{t}}\right) \cdot \Pi_{\mathrm{t}=1}{ }^{\mathrm{n}}\left(1+\mathrm{r}_{\mathrm{t}}\left(\theta_{\mathrm{t}}\right)^{\mathrm{t}}\right]-\mathrm{I}_{0} .\right.
$$

If we assume deductions from the asset value over time, say $d_{t}$ at time $t$, then expression (6) takes the form,

$$
\mathrm{W}(\theta)=\sum_{\mathrm{t}=1}{ }^{\mathrm{n}}\left(1-\mathrm{d}_{\mathrm{t}}\right) \mathrm{A}_{\mathrm{t}}\left(\theta_{\mathrm{t}}, \mathbf{x}_{\mathrm{t}}\left(\theta_{\mathrm{t}}\right)\right)=\sum_{\mathrm{t}=1}{ }^{\mathrm{n}}\left[\left(1-\mathrm{d}_{\mathrm{t}}\right) \mathrm{A}_{\mathrm{t}}\left(\theta_{\mathrm{t}}\right) \cdot \Pi_{\mathrm{t}=1}{ }^{\mathrm{n}}\left(1+\mathrm{r}_{\mathrm{t}}\left(\theta_{\mathrm{t}}\right)^{\mathrm{t}}\right]-\mathrm{I}_{0}\right.
$$

The simulation of $\mathrm{W}$ is now subject to the complementary recursive relations,

$$
r_{t}=f_{t}\left(\theta_{t-1}, r_{t-1}\right) \text {, }
$$

where, $r_{t}$ itself can be an expected value of a system of rates of returns obtained from the debt-swap portfolio with different contingencies across diverse projects that may prevail. This part of the contingency-based averaging process is not shown. $r_{t}$ would be better represented by geometric averaging rather than arithmetical averaging of profit-sharing rates. That is due to the underlying term-structure of the rates that vary according to different contingencies and restructuring of portfolios. All these are simulated under nonlinear complexity due to recursive knowledge induction over time and contingencies. 
On the $\theta$-assignment problem, as in the shuratic discursive process shown above we note,

$$
\theta_{\mathrm{t}}=\lim _{\mathrm{i}=1 \rightarrow \mathrm{m}}\left\{\theta_{\mathrm{ti}}\right\}
$$

Interaction at time $\mathrm{t}$ are denoted by $\mathrm{i}=1,2, \ldots \mathrm{m} ; \mathrm{t}=1,2, \ldots, \mathrm{n}$.

Several equity projects, $I_{\mathrm{ts}}$ say, $\mathrm{s}=1,2, . ., \mathrm{s} ; \mathrm{t}=1,2, . ., \mathrm{n}$ can be used in swapping debt and risk. The overlapping generation model then is like a sinking fund with foreign investment or equity flows:

$$
\mathrm{W}=\Sigma_{\mathrm{s}} \Sigma_{\mathrm{t}} \mathrm{A}_{\mathrm{ts}}\left(\theta_{\mathrm{ts}}, \mathbf{x}\left(\theta_{\mathrm{ts}}\right)\right)=\Sigma_{\mathrm{s}} \Sigma_{\mathrm{t}}\left[\mathrm{A}_{\mathrm{ts}} \Pi_{\mathrm{t}=1}{ }^{\mathrm{n}}\left(1+\mathrm{r}_{\mathrm{ts}}\right)^{\mathrm{t}}\right]\left[\theta_{\mathrm{ts}}\right]-\Sigma_{\mathrm{s}} \Sigma_{\mathrm{t}} \mathrm{I}_{\mathrm{ts}}\left(\theta_{\mathrm{ts}}\right)
$$

The complementary recursive relations are once again of the type,

$$
r_{j s}=f\left(\theta_{j-1, s}, r_{j-1, s}\right) \text {, }
$$

where, $\mathrm{r}_{\mathrm{ts}}$, means the profit-sharing rates in a project that is co-operatively complemented with other projects, $\mathrm{s}=1,2, \ldots, \mathrm{s}$ '. Such joint venture projects can be understood as multilateral socioeconomic projects in the Islamic community. See appendix.

\section{Rejection of Time-Value of Money and Discounting Methods}

The method of spot-valuation of risk and return along the simulated line of occurrence of prospects and contingencies over time suggest that future risk is neither known nor computable. Risk measurement is therefore enacted at the proximity of a point of valuation over time in the overlapping generation model.

If the risk is not fully known in the future, then the characteristics of the good also remain unknown (Hirshleifer, 1970). Hence future goods are differentiated goods. Besides, since such differentiated goods remain undetermined in their characteristics, such as for example the disappearance of many endangered species in the future, therefore, there is no complete market for such goods. Thereby, no form of exchange mechanism can be ascertained in futures. Finally, in the face of incomplete markets caused by preference dynamics, and the disappearance of particular goods and services or the existence of only differentiated ones, there cannot be fully determined financial relations with the real economy in the futures of asset-valuation. Consequently, particular kinds and volumes of resource mobilization by means of particular kinds of financial instruments cannot be fully determined, despite probability measures attached to future prospects.

These arguments militate against the validity of discounting and the use of corresponding kinds of asset-valuation models. The Prophet Muhammad said that the price of fruits cannot be set before they are borne; the price of fish cannot be determined before it is landed into markets. The Prophet ruled that 
exchange of similar goods for similar goods (hence services) is riba unless they are exchanged on the spot and without debasement of circulating currency. Today this principle is particularly true in regards to devaluation of money in circulation. The principle was continued on during the classical Islamic period of history. Imam Ghazali's conception of distributive equity was centered on the money, currency and real worth interrelationships (Imam Ghazali trans. Karim, undated). Money as currency that was debased by corrupted shape, material and value was seen as debased currency in circulation, and therefore carried lower value.

\section{Part 4 \\ A Quantitative Issue in the Overlapping Generation Asset-valuation Model}

The principal information required for the overlapping generation valuation model is the limiting value $\theta_{\mathrm{t}}$ (weights) of the discoursed knowledge values $\left\{\theta_{\mathrm{tj}}\right\}$ over interactions ( $\mathrm{t}$ at time ti) and integration $(\mathrm{j})$. Next there is the data requirement for the knowledge-induced socioeconomic, financial and policy variables, all encapsulated in $\left\{\mathbf{x}_{\mathrm{t}}\left(\theta_{\mathrm{t}}\right)\right\}$. These enter ensemble the $\mathrm{W}\left(\theta_{\mathrm{t}}, \mathbf{x}_{\mathrm{t}}\left(\theta_{\mathrm{t}}\right)\right)$ function. The important aspect of the feedback shown in Fig. 5 brings out the specific nature of information generation for the overlapping generation valuation model.

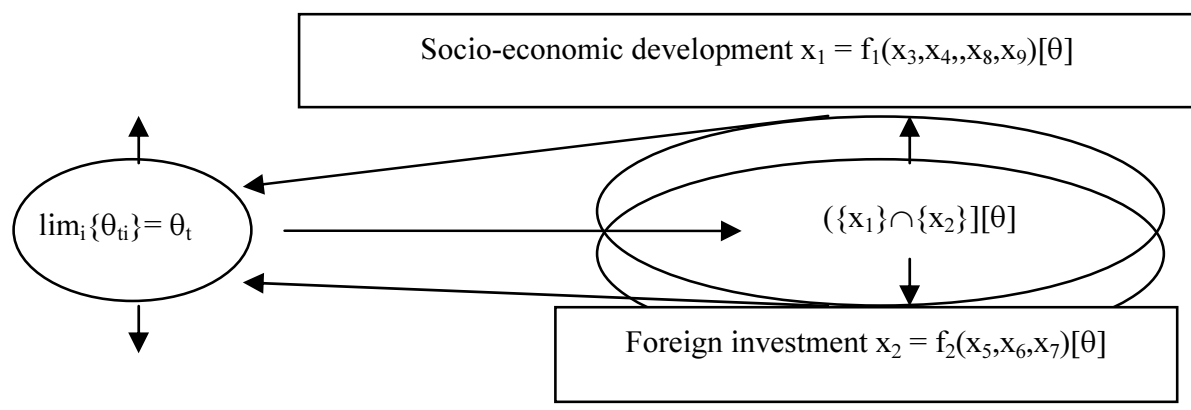

Fig. 5. Recursive feedback and knowledge-induced expansion of the interactive, integrative and evolutionary sets.

There are two ways of generating $\theta_{\mathrm{t}}$-values and the $\left[\left\{\mathrm{x}_{1}\right\} \cap\left\{\mathrm{x}_{2}\right\}\right]\left[\theta_{\mathrm{t}}\right]$ feedback by circular causation:

1. The discursive shuratic process is based on the methodology of rhetoric of economics and is adopted at every point of interaction, integration (consensus value) along the asset-valuation path (McCloskey, 1985). These institutionally assigned values out of discourse take up ordinal $\theta_{\mathrm{t}}$-weights. 
2. $\theta_{\mathrm{t}}$-values as weights are the assigned numerical values, such as, $\theta_{\mathrm{t}} \geq$ 1(high value), $1 / 2 \leq \theta_{\mathrm{t}} \leq 1$ (medium value), $0 \leq \theta_{\mathrm{t}} \leq 1 / 2$ (low value) based on the performance of the guidance and policies in concert with socioeconomic realities.

3. The $\left\{\theta_{t}, \mathbf{x}_{t}\left(\theta_{t}\right)\right\}$-values are then recursively determined.

An example of estimating such recursively determined weighted values of $\left\{\theta_{\mathrm{t}}, \mathbf{x}_{\mathrm{t}}\left(\theta_{\mathrm{t}}\right)\right\}$ appears in Choudhury (2006c).

As an illustrative example, we can specify the parameters as follows to indicate a range of parametric variations of $\theta$-values in the simulation of the overlapping generation asset-valuation model upon which rats of return will hinge:

The rate of return, ' $r$ ' is taken to be monotonous increasing (decreasing) along with the equity/debt swap ratio, ' $\delta$ '. While ' $r$ ' is market determined, ' $\delta$ ' is institutionally determined out of discourse in concert with Islamic development financing possibilities and the socioeconomic realities. To these we connect the experience of previous Principle-Agent preference changes at large caused by knowledge-induction on the socioeconomic development perspective. In the Islamic case such development regimes are established by dynamic lifefulfilling possibilities.

$$
\begin{aligned}
& 20 \% \leq \delta=(\mathrm{I} / \mathrm{D})[\text { take as } 1 \leq \theta] \leq 50 \%, \text { or, } 10 \% \leq \mathrm{r} \leq 20 \% ; \\
& 10 \% \leq \delta=(\mathrm{I} / \mathrm{D})[\text { take as } 1 / 2 \leq \theta \leq 1] \leq 20 \%, \text { or, } 5 \% \leq \mathrm{r} \leq 10 \% ; \\
& 0 \% \leq \delta=(\mathrm{I} / \mathrm{D})[\text { take as } 0 \leq \theta \leq 1 / 2] \leq 10 \%, \text { or, } 0 \% \leq \mathrm{r} \leq 5 \% .
\end{aligned}
$$

By using such weights and values of the control variables the overlapping generation model estimation can be launched along with given $A_{\mathrm{ts}}\left(\theta_{\mathrm{ts}}, \mathrm{x}\left(\theta_{\mathrm{ts}}\right)\right)$ values. Determination of such weights is the most difficult matter in Islamic asset-valuation as the compounding of preferences, market responses and institutions is invoked at every spot point of asset-valuation. The underlying focus here is how debt can be phased out by profitable equity-swaps using foreign investments in national assets.

\section{Part 5 \\ Conclusion}

True Islamic financial engineering perspectives must be based on the essential Islamic worldview. From this worldview is derived the methodology that we explained in this paper by the TSR. Such a methodological worldview is then brought to bear on the reconstruction of Islamic economic and financial studies just as in every other issue and problem of intellectual inquiry. The TSR 
is unique and universal by virtue of its singular premise of explanation of entire reality by the dynamics of pervasive learning signified by the principle of pervasive complementarities between the good things of life. Through learning premised on the unity of divine knowledge (Tawhid) moral values and economic and financial systems are endogenously generated by the momentum of the unification dynamics.

We have noted that in the field of financial engineering as a special case of application of TSR, the overlapping generation model in the Islamic context has its ramifications that are quite contrary to the mainstream ones. The TSR methodology applied to asset-valuation, in contradistinction to the risk-return analysis of futures in mainstream financial engineering, seriously questions the received asset-valuation methodology in prevalent Islamic economics and finance and as used by the Islamic financial institutions. Much remains to be reconceptualized by the full formalism of the Tawhidi worldview in Islamic financial engineering.

This paper among many of its kind has brought the Tawhidi methodology to bear on the topic of asset-valuation by the formalism of an overlapping generation model in the light of TSR methodology. Thereby, many of the accepted notions among mainstream Islamic economists and financial experts are rejected. Indeed, the essential nature of the Tawhidi unity of knowledge in economic and socioeconomic issues cannot be found in any other paradigm including the prevalent thinking in Islamic economics and finance. This is due to the fundamental opposite meaning, understanding and implications of the principle of pervasive complementarities in the light of Qur'anic epistemology, against the postulate of trade-off in resource allocation premised on scarcity, competition, optimization and steady-state equilibrium states of differentiated entities in every other socio-scientific reasoning. Unity of knowledge is organic in nature, and according to this morality and ethics, are learned as in the IIEprocesses (shuratic processes). Contrarily, morality and ethics are either neutral or remain exogenous and cost-incurring in differentiated relations of the neoclassical and neo-liberal worldview.

A computer-assisted overlapping generation model of the TSR vintage as a critique and replacement of the present-value asset-valuation model will replace the unacceptable concept of time-value of money, discounting in Islamic economic and financial reasoning and dealing, and all the risk-return misconceptions that have been artificially cultivated. The overlapping generation model once computerized can be available for use by Islamic financial institutions, policy-makers and researchers in using the genuinely Shariah-compliant asset-valuation in the light of the Qur'an and the Sunnah. 
Such a work has not been developed in the area of Islamic economics and finance although its need is a pressing one to prove the applicability of the truly Shariah-compliant business, transaction and financial asset-valuation in the absence of the riba-shadow price of the time-value of money. Important moral, institutional, socioeconomic and financial implications lie embedded in the approach and argumentative formalism presented in this paper.

Indeed, despite my total disagreement with Bruteau's (1997) pantheistic depiction of unity between God and the universe, the following passage is illuminating in depicting the meaning of the divine in our worldly experience:

If you can see the God you love present in, even as, this world, then feel that union and rejoice in that. And be active in it, contribute to it, participate in the building, in the artwork, in the healing, in the understanding. This is where Reality is. You yourself are both a member of the Finite and a member of the Infinite....

\section{References}

Bakar, O. (1991) Tawhid and Science, Science University of Malaysia, Secretariat for Islamic Philosophy and Science, Penang, Malaysia.

Barrow, J.D. (1991) Theories of Everything, The Quest for Ultimate Explanation, Oxford, Eng: Oxford University Press.

Bruteau, B. (1997) God's Ecstasy, p. 179, New York, N.Y: The Crossroad Publishing Co.

Chittick, W.C. (1989) Sufi Path of Knowledge, Albany, NY: State University of New York.

Choudhury, M.A, Zaman, S.I. and Al-Nasr, Y. (2007 forthcoming) "A knowledge-induced Operator Model", Journal of Science, Sultan Qaboos University.

Choudhury, M.A. (2000) "Venture Capital in Islam: A Critical Examination", Journal of Economic Studies, 28:1.

Choudhury, M.A. (2006a) Methodological Issues and Themes in the Koran, being Vol. 1 of his Science and Epistemology in the Quran, Lewiston, N.Y: The Edwin Mellen Press.

Choudhury, M.A. (2006b) Monotheism Applied to Social Issues in the Koran, being Vol. 4 of his Science and Epistemology in the Quran, Lewiston, N.Y: The Edwin Mellen Press.

Choudhury, M.A. (2006c) Circular Causation Model in the Koran, being Vol. 3 of his Science and Epistemology in the Koran, Lewiston, N.Y: The Edwin Mellen Press.

Choudhury, M.A. (2006d) "Evolutionary Equilibrium in Learning Spaces of Unity of Knowledge", Middle East Business and Economic Review, 18:2.

Choudhury, M.A. and Hoque, M.Z. (2004) An Advanced Exposition of Islamic Economics and Finance, Chap. 2, Lewiston, N.Y: The Edwin Mellen Press.

Ebrahim, M.S. and A-H Bashir (1999) "On the Design and Efficiency of a Participating Growth Bill”, The Quarterly Review of Economics and Finance, 39: 513-527.

El-Gamal, M. (2007) "Incoherent Pietism and Sharia Arbitrage", Financial News, May 23.(http://uk.biz.yahoo.com/23052007/399/opinion-mahmoud-el-gamal-incoherentpietism-sharia-arbitrage.html )

Friedman, M. (1989) "Quantity Theory of Money", pp: 1-40, in: J. Eatwell, M. Milgate, and P. Newman (eds.) The New Palgrave: Money, New York, NY: W.W. Norton.

[Imam] Ghazzali, trans. D. Buchman, (1998) The Niche of Lights, Provo, Utah: Brigham Young University Press.

[Imam] Ghazzali A.H. trans. M.E. Marmura (1997) The Incoherence of the Philosophers, Provo, Utah: Brigham Young University Press. 
Godel, K. (1965) "On formally Undecidable Propositions of Principia Mathematica and Related Systems", in: M. Davies (Ed.) The Undecidable, New York: Raven Books.

Gruber, T.R. (1993) "A Translation Approach to Portable Ontologies", Knowledge Acquisition, 5(2): 199-200.

Hammond, P.J. (1989) “On Reconciling Arrow's Theory of Social Choice with Harsanyi's Fundamental Utilitarianism", in: G.R. Feiwel ed. Arrow and the Foundation of the Theory of Economic Policy, pp: 179-221, London, Eng: Macmillan.

Harsanyi, J.C. (1955) "Cardinal Welfare, Individualistic Ethics, and Interpersonal Comparisons of Utility", Journal of Political Economy, 63: 309-21.

Heidegger, M. and Hofstadter, A. (1988) "The Thesis of Modern Ontology: The Basic Ways of Being are the Being of Nature (res extensa) and the being of mind (res cogitans)", in The Basic Problems of Phenomenology, Bloomington \& Indianapolis, IN: Indiana University Press, pp: 122-224.

Hirshleifer, J. (1965) "Investment Decisions under Uncertainty: Choice-theoretic Approach", The Quarterly Journal of Economics (LXXIX:4), pp: 509-536.

Hirshleifer, J. (1970) Investment, Interest and Capital, Englewoods, Cliffs, NJ: Prentice-Hall, Inc.

Jabsheh, F., Behbehani, W., Al-Shamali, S. and Dashti, B. (2007) The Impact of Financial Liberalization on the Islamic Banking Industry, Mimeo. Kuwait Institute of Scientific Research, Kuwait.

Jean, W.H. (1970) The Analytical Theory of Finance, Chap. 2, Toronto, On: Holt, Rinehart \& Winston, Inc.

Kahf, M. (2007) "Bridging the Gap, Islamic finance is a way to bring the Muslim and Western worlds together", Business Islamica, January-February, pp: 64-66.

Karim, F. (n.d.) Imam Ghazzali's Ihya Ulum-Id-Din, Lahore, Pakistan: Shah Muhammad Ashraf.

Kellert, S.H. (1993) In the Wake of Chaos, Chap. 4. Chicago, ILL: University of Chicago Press.

Khan, M.F. (1996) "Time Value of Money and Discounting in Islamic Perspectives", Review of Islamic Economics, 1(2): 35-45.

Kolb, R.W. (1994) Understanding Futures Markets. Kolb Publishing, Miami, Florida, Chap. 12: "An Options Primer".

McCloskey, D.N. (1985) The Rhetoric of Economics, Madison, Wisconsin, The University of Wisconsin Press.

Mydin, A.K. and Larbani, M. (2006) "Part I: Seigniorage of Fiat Money and the maqasid alShari'ah: the unattainableness of the maqasid, Humanomics, International Journal of Systems and Ethics, 22(1): 17-33.

O'Donnell, R.M. (1989) "Types of Probabilities and Their Measurement", :50-66, also "Epistemology", in his Keynes: Philosophy, Economics \& Politics, :81-105, London, Eng: Macmillan Press Ltd.

Rasmussen, T.N. and Rutherford, T.F. (2001) "Modeling Overlapping Generation in A Complementarity Format", internet version.

Rosly, S.A. (2005) Critical Issues on Islamic Banking and Financial Markets, Kuala Lumpur, Malaysia: Dinamas.

Rucker, R. (1982) Infinity and the Mind, :273-286. New York, N.Y: Bantam Books.

Salvatore, D. (2004) Managerial Economics in a Global Economy, Thomson Inc. :11-12.

Smullyan, R.M. (1992) Godel's Incompleteness Theorems, New York: Oxford University Press.

Tobin, J. (1958) "Liquidity Preference As Behavior Toward Risk", Review of Economic Studies, (XXVI:1): 65-86.

Von Mises, L. (1976) The Ultimate Foundation of Economic Science, Kansas City, Kansas, Sheed Andrews \& McMeel.

Note: All Qur'anic Verses are taken from Abdullah Yusuf Ali trans. The Holy Qur'an, Text, Translation and Commentary (1946). 
Appendix

\title{
The Extended Social Nature of Financial Engineering in Islamic Perspective
}

\author{
Equity Financing \\ Unity of Knowledge in the Shariah $\left[\Omega \rightarrow_{\mathrm{F}}\{\theta\} \rightarrow_{\mathrm{f}^{*}} \theta^{*}=\right.$ consensual value $]$ \\ Human resource development \\ Preference formation according \\ to the Shariah \\ social trust on an enterprise \& \\ project \\ consumer satisfaction developed \\ by participation and trust

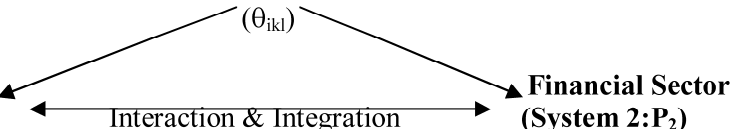 \\ Interaction \& Integration $\longrightarrow$ (System 2:P $)$ \\ appropriate joint \\ venture, joint \\ Production menus \\ avoidance of$$
\downarrow
$$ \\ speculation \\ risk-diversification \\ Average Total Cost reduction \\ stable returns \\ shareholding \\ stakeholding

\section{$\left(\theta_{\mathrm{ikl}}, \mathbf{x}_{\mathrm{ikl}}\left(\theta_{\mathrm{ikl}}\right)\right)$ : Real Economy, $\mathrm{P}_{1}$

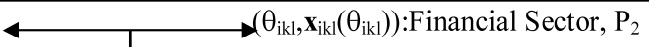 \\ Project Evaluation by the Socỉal Wellbeing: $\mathrm{W}\left(\theta_{\mathrm{ikl}}, \mathbf{x}_{\mathrm{ikl}}\left(\theta_{\mathrm{ikl}}\right)\right)$ :}

Real Economy

(System 1: $\mathbf{P}_{1}$ )

Spending in the real

economy according to

Shariah rules: resource

Mobilization

productivity

product diversification

sustained economic growth

economic efficiency

economic stability

An example is the overlapping generation asset-valuation model

Evolution into New $\left[\theta_{\mathrm{ikl}}\right]$ by re-invoking $\left[\Omega \rightarrow_{\mathrm{F}}\{\theta\} \rightarrow_{\mathrm{f}^{*}} \theta^{*}=\right.$ consensual value<smiles>C[14C](=O)[14CH2][14CH3]</smiles>

Fig. A1. An Example of Critical Complementary Relations between Socio-Economic and Policy Variables. 
Enterprise Planning

Economic Planning

Portfolio Mix: Short, Medium \& Long Run Projects and Project Financing

$\underline{\text { Input }}$

Share capital

Financial instruments

Project selection

Socio-economicshareholdi

Variables \& relations $\underline{\text { Output }}$

profitability \& returns

buyers' preference \& satisfaction

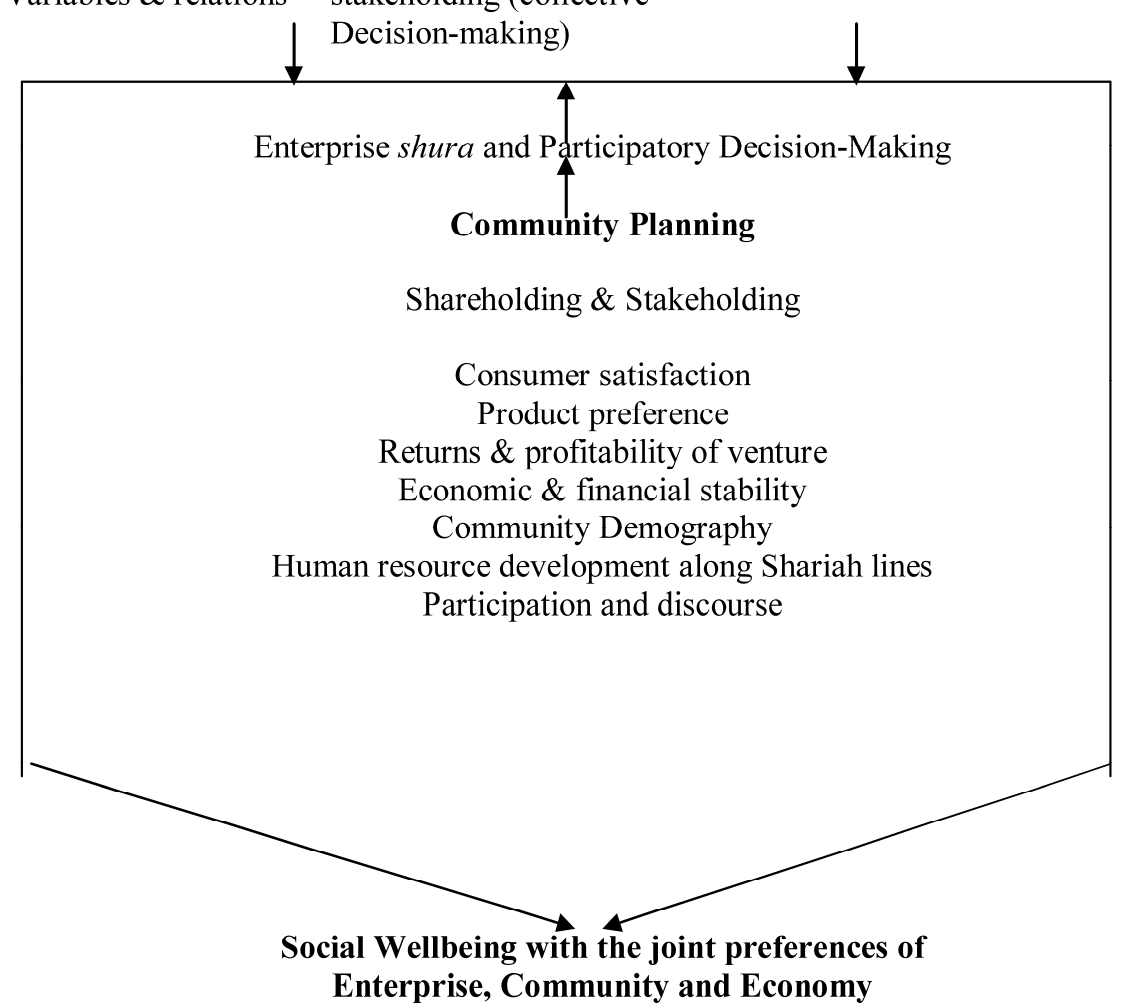

Fig. A2. Strategic Interrelationships: Enterprise, Economy and Community. 
النقد و البديل الإسلامي لقضايا الهندسة المالية

\author{
مسعود العالم شودري \\ كلية التجارة والاقتصاد \\ جامعة السلطان قابوس - سلطنة عمان - وجامعة تريباكتي \\ برنامج الدراسات العليا في الاقتصاد الإسلامي والتهويل \\ الدستخلص. بنيت حجج هذه الورقة على المسلمات الاقتـصادية \\ و المنهجية حول السلوك، و الأسواق، و التركيب المؤسسي التي تؤثر

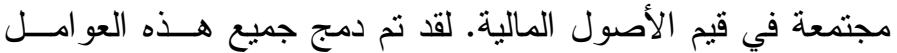 \\ لتفسير كيف تعمل المنهجية على تحديد مجال الهندسة المالية مسنـ \\ المنظور السائد والمنظور الإسلامي. كما تم فحص الهندسة المالية

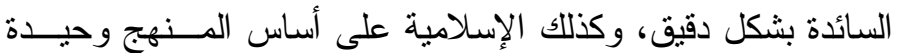 \\ العلوم أبي المنهج التوحيدي.
}

